\title{
Peptides and proteins used to enhance gold nanoparticle delivery to the brain: preclinical approaches
}

This article was published in the following Dove Press journal:

International Journal of Nanomedicine

10 August 2015

Number of times this article has been viewed

\author{
Carolina Velasco-Aguirre ${ }^{1,2, *}$ \\ Francisco Morales 1,2,* \\ Eduardo Gallardo-Toledo 1,2 \\ Simon Guerrero 1,2 \\ Ernest Giralt ${ }^{3,4}$ \\ Eyleen Araya ${ }^{5}$ \\ Marcelo J Kogan ${ }^{1,2}$ \\ 'Departamento de Química \\ Farmacológica y Toxicológica, \\ Facultad de Ciencias Químicas y \\ Farmacéuticas, Universidad de Chile, \\ ${ }^{2}$ Advanced Center for Chronic \\ Diseases (ACCDiS), Santiago, Chile; \\ ${ }^{3}$ Institute for Research in Biomedicine \\ (IRB Barcelona), Barcelona, Spain, \\ ${ }^{4}$ Department of Organic Chemistry, \\ University of Barcelona, Barcelona, \\ Spain; ${ }^{5}$ Departamento de Ciencias \\ Químicas, Facultad de Ciencias \\ Exactas, Universidad Andrés Bello, \\ Andrés Bello, Santiago, Chile \\ *These authors contributed equally \\ to this work
}

Correspondence: Marcelo J Kogan Departamento de Química Farmacológica y Toxicológica, Facultad de Ciencias Químicas y Farmacéuticas, Universidad de Chile, Santos Dumont 964, Independencia, Santiago, Chile Tel +56 229782897

Email mkogan@ciq.uchile.cl

\begin{abstract}
An exciting and emerging field in nanomedicine involves the use of gold nanoparticles (AuNPs) in the preclinical development of new strategies for the treatment and diagnosis of brain-related diseases such as neurodegeneration and cerebral tumors. The treatment of many brain-related disorders with AuNPs, which possess useful physical properties, is limited by the blood-brain barrier (BBB). The BBB highly regulates the substances that can permeate into the brain. Peptides and proteins may represent promising tools to improve the delivery of AuNPs to the central nervous system (CNS). In this review, we summarize the potential applications of AuNPs to CNS disorders, discuss different strategies based on the use of peptides or proteins to improve the delivery of AuNPs to the brain, and examine the intranasal administration route, which bypasses the BBB. We also analyze the potential neurotoxicity of AuNPs and the perspectives and new challenges concerning the use of peptides and proteins to enhance the delivery of AuNPs to the brain. The majority of the work described in this review is in a preclinical stage of experimentation, or in select cases, in clinical trials in humans. We note that the use of AuNPs still requires substantial study before being translated into human applications. However, for further clinical research, the issues related to the potential use of AuNPs must be analyzed.
\end{abstract}

Keywords: blood-brain barrier, central nervous system, transcytosis, drug delivery, EPR effect, biodistribution

\section{Introduction}

Nanotechnology offers new potential tools for diagnostics and therapy. Metal nanoparticles, notably gold nanoparticles (AuNPs), have unique features that could contribute to the development of new strategies for the so-called theranostics (therapy and diagnostics in a single procedure) ${ }^{1-3}$ Because of their optical and electric properties, different forms of AuNPs, such as gold nanospheres (GNSs), gold nanorods (GNRs), silica/gold nanoshells, and hollow GNSs, have been studied for biomedical applications including imaging, biosensing, photothermal and microwave therapy, and the delivery of either genes or antitumor drugs for cancer diagnosis and therapy. ${ }^{1,4}$ This review is focused on the improvement of the delivery of AuNPs to the brain for potential uses in the preclinical treatment and diagnosis of central nervous system (CNS) disorders instead of the application of AuNPs to drug delivery.

An exciting and emerging field involves the use of AuNPs for the development of new tools for the treatment of brain-related diseases such as neurodegeneration and brain tumors, and includes the use of GNSs to destroy in vitro the $\beta$-amyloid aggregates involved in Alzheimer's disease. ${ }^{2,5,6}$ However, as discussed by Krol, ${ }^{7}$ the delivery of 
nanoparticles to the brain remains unresolved because of the following: I) the interaction of nanoparticles with biological components after administration; II) physical parameters such as the blood flow, residence time on target molecules, and the ratio of diseased to healthy cells; and III) the lack of unique target biomarkers for the diseased cells and the presence of highly selective barriers. ${ }^{7}$ Thus, the treatment of many brain-related disorders using various drugs or nanoparticles is limited because of the presence of the blood-brain barrier (BBB), which highly regulates drug permeation. Peptides and proteins could represent a promising tool to improve the delivery of AuNPs. Moreover, AuNPs can be capped with peptides specific to selective targets, which is called active targeting. In the "AuNPs for the development of new strategies for therapy and diagnostics of CNS disorders: preclinical applications" section of this review, we summarize the preclinical applications of AuNPs to CNS disorders. In the "BBB and permeation mechanisms" section, we provide a description of the BBB and the possible mechanisms by which peptides, proteins, and AuNPs cross this barrier. In the "What impedes or assists AuNPs in permeating the BBB?" section, we discuss the use of peptides and proteins as a strategy to improve the brain delivery of AuNPs and the intranasal administration to circumvent the BBB. Finally, we discuss the potential neurotoxicity of AuNPs and the perspectives and new challenges concerning the use of peptides to enhance the delivery of AuNPs to the brain.

\section{AuNPs for the development of new strategies for therapy and diagnostics of CNS disorders: preclinical applications}

The potential application of AuNPs to the treatment and diagnostics of pathologies related to the CNS, such as neurodegenerative disorders and brain tumors, is an emerging field. However, the difficulty of crossing the BBB must be overcome. Although the clinical application of AuNPs remains an incipient field, examples of preclinical applications that could be useful can be provided for the development of future strategies for therapy and diagnosis of neurodegenerative disorders in the CNS.

For the in vivo inhibition of prion protein aggregation, conversion, and replication in mice in the field of neurodegenerative disorders, ${ }^{8}$ GNSs were capped with albumin using the layer-by-layer methodology, which resulted in high anti-prion activity after a single intracerebral dose of nanoparticles. In another study, the identical group examined the biodistribution of polyelectrolyte multilayer-coated GNSs in mice by near-infrared time-domain imaging. ${ }^{9}$ These nanoparticles were observed to cross the $\mathrm{BBB}$, accumulate in specific regions of the brain, and enter defined neuronal structures, suggesting active uptake instead of barrier damage-induced leakage. GNSs accumulated in close proximity to the toxic protein aggregate areas such as prion or $\beta$-amyloid aggregates; GNSs may therefore be applicable to the treatment of Creutzfeldt-Jakob and Alzheimer's diseases. However, in the latter work, the authors did not provide information related to the percentage of the injected dose (ID) that reaches the brain. This last point is relevant because, in many cases, nanoparticles are accumulated in the liver and spleen, which may result from the retention by the reticuloendothelial system (RES) and could limit the use of GNSs. Another application, which was developed by our group, involved the conjugation of $12 \mathrm{~nm}$ GNSs with the amphipathic peptide CLPFFD for the in vitro disaggregation of $\beta$-amyloid toxic aggregates present in the brains of Alzheimer's disease patients. ${ }^{2,5,6}$ In addition, we recently conjugated the identical peptide to $\mathrm{GNRs}^{2}$ to produce a photothermal ablation of $\beta$-amyloid. Two other groups conjugated fragments of the $\beta$-amyloid peptide ( $\beta$-amyloid (31-35) and $\beta$-amyloid (25-35)) with AuNPs, resulting in the photothermal ablation of $\beta$-amyloid. ${ }^{10}$

AuNPs have been used as adjuvants for therapeutic agents in spinal cord injuries in animal models. Wang et al investigated the effects of AuNPs on axonal and functional recovery in spinal cord-injured rats using $15 \mathrm{~nm}$ GNSs conjugated with the human NgRFc fusion protein. ${ }^{11}$ The Nogo-66 receptor is the target of human NgRFc. This receptor mediates neurite outgrowth in the adult mammalian CNS. Adult rats immunized with the protein vaccine produced more anti-Nogo-66 receptor antibodies compared to rats treated by the methods that are currently in use. This AuNP-conjugated system is a novel strategy that uses vaccination to treat spinal cord injuries and can efficiently promote repair in spinal cordinjured rats.

Chien et al demonstrated a new diagnostic tool for brain tumors consisting of GNSs conjugated with polyethylene glycol (PEG) which accumulate in tumor tissues, as shown by tomography and X-ray microscopy, due to the enhanced permeation and retention (EPR) effect. ${ }^{12}$ With appropriate staining, complicated tissue structures, such as the cerebellum, have been imaged using high-resolution X-ray microscopy. These results have provided notable qualitative and quantitative information covering the accumulation of PEG-GNSs in tumors. However, PEG-coated gold nanocages 
have been investigated as near-infrared contrast agents for photoacoustic tomography of the rat cerebral cortex in vivo. ${ }^{13}$ Compared with silica/gold nanoshells, gold nanocages have exhibited better results for in vivo applications, resulting in up to $81 \%$ enhancements of the optical absorption in the cerebral cortex during experiments. This finding could result from the gold nanocages being more compact in size ( $<50 \mathrm{~nm}$ vs $>100 \mathrm{~nm}$ for silica/gold nanoshells) and their absorption-dominant extinction. Other nanomaterials have been investigated for the identical purpose. PEGylated hollow GNSs have been used as a contrast agent for photoacoustic tomography. ${ }^{14}$ Images of the brain vasculature with high spatial resolutions and enhanced sensitivities were obtained 2 hours after intravenous injection. GNRs penetration in CNS in a focused ultrasound-induced BBB-opening model in vivo can be monitored via photoacoustic microscopy. ${ }^{15}$ However, GNRs can exhibit a certain degree of toxicity, as discussed by Adura et al because of the presence of the surfactant cetyl trimethylammonium bromide (CTAB) used in their synthesis. ${ }^{2}$ However, different strategies have been developed for potential applications such as the use of peptides, polymers, or phospholipid caps.

Finally, on the topic of the preclinical applications of AuNPs to diagnosis and therapy, select applications of AuNPs to therapy in clinical fields are noted, as reported by Etheridge et al. ${ }^{16}$ However, many of these treatments are not currently approved but are only in clinical trials. One example is the potential use of GNSs labeled with recombinant human tumor necrosis factor alpha to target solid tumors in advanced-stage cancer patients; ${ }^{17}$ however, this research is only in Phase II clinical trials.

\section{BBB and permeation mechanisms}

In this section, we provide a brief discussion of the architecture of the $\mathrm{BBB}$ and the permeation mechanisms with a focus on crossing mechanisms related to peptides, proteins, and AuNPs.

\section{BBB architecture}

Neurons of the CNS require chemical and electrical signals for their proper function; thus, the ionic environment and the regulation of the substances across their membranes are critical. These membranes are the epithelium of the choroid plexus, ${ }^{18}$ the epithelium of the arachnoid mater, ${ }^{19}$ and the endothelium of the brain microvessels. Combined, they are called the BBB. ${ }^{20}$ The generation of these membranes, or cellular barriers, has been suggested to result from evolutionary pressure to generate a mechanism that maintains homeostasis by regulating the transport of substances between the blood and the CNS. ${ }^{21}$ One of the most important barriers of the CNS is the BBB. The BBB contains the largest interface between the blood and the CNS and is crucial for the maintenance of CNS homeostasis. ${ }^{22}$ The endothelial cells that constitute this barrier, the basement membrane, pericytes, astrocytes, and microglial cells comprise the neurovascular unit. The pericytes and astrocytes play a substantial role in the formation and differentiation of the CNS vasculature (Figure 1). ${ }^{23}$ The endothelial cells that form the BBB generate complexes of tight and adherent junctions and create a physical barrier that blocks paracellular transport. ${ }^{24}$ Approximately, one-third (37\%) of the circumference of the endothelial tube is covered by pericytes, and two-thirds (63\%) of the endothelial tube is sheathed by astrocytic endfeet. ${ }^{25}$

Astrocytes in the CNS perform diverse functions. The endfeet of astrocytes are involved in a number of transport processes at the brain-blood interface. Astrocytes are the support for metabolic homeostasis via facilitating complex interactions between the blood vasculature, the interposing cerebrospinal fluid, and surrounding interstitial fluid. Astrocytes extend dense, laminal processes that comprise the glial-limiting membrane, a selectively permeable structure that forms a boundary between CNS tissue and the cerebrospinal fluid in the subarachnoid spaces and throughout the ventricular system. ${ }^{26}$ An additional barrier is formed by astrocytic "endfoot" processes juxtaposed to the cerebrovasculature, permitting the bidirectional communication between neurons and astrocytes in addition to enabling astrocytes to communicate with the supplying circulations of the blood and cerebrospinal fluid. ${ }^{26,27}$ Paravascular astrocytic processes sheath $97 \%$ of the entire cerebrovasculature, leaving only $20 \mathrm{~nm}$ clefts between endfeet and blood vessels whereas forming small channels that allow the cerebrospinal fluid in the subarachnoid space to flow into the brain along the exterior of the entire blood circulatory pathway. ${ }^{25}$ Once cerebrospinal fluid enters paravascular spaces, the cerebrospinal fluid may selectively exchange its soluble contents with the interstitial fluid of the brain parenchyma. The directional influx of cerebrospinal fluid into the brain along para-arterial spaces and efflux along para-venous spaces facilitates the bulk flow clearance of interstitial solutes including dextrans of various molecular sizes, inulin, and soluble $\beta$-amyloid. ${ }^{28}$ In peripheral tissues, the bulk flow of interstitial solutes deposits wastes from cellular metabolism in the secondary circulation provided by the lymphatic system. Paravascular cerebrospinal fluid channels, aided by astrocytes, facilitate 


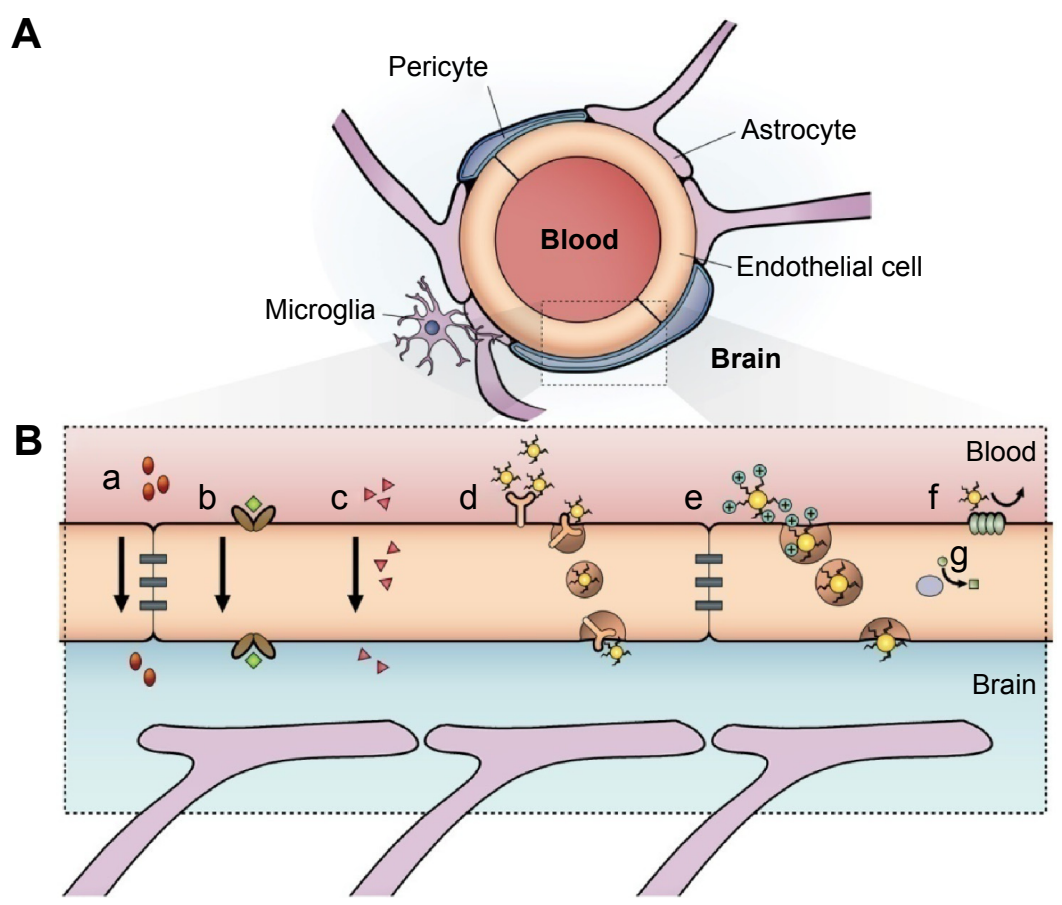

Figure I Schematic representation of the blood-brain barrier.

Notes: (A) Scheme of the neurovascular unit that constitutes the BBB. This unit contains the pericytes and astrocytes, which play an important role in the formation and differentiation of the CNS vasculature. (B) The main routes of the crossing of molecules to the CNS are represented. (a) A representation of the tight junctions severely restricting the penetration of water-soluble compounds, including polar drugs. (b) The endothelium contains transport proteins (carriers) for glucose, amino acids, purine bases, nucleosides, choline, and other substances. Some transporters are energy dependent (eg, P-glycoprotein) and act as efflux transporters (eg, azidothymidine). (c) An effective diffusive route for lipid-soluble agents to cross the membranes of the endothelium. (d) Certain proteins, such as insulin and transferrin, are taken up by specific receptormediated endocytosis and transcytosis. Nanoparticles capped with these molecules can cross the BBB. (e) Native plasma proteins such as albumin are poorly transported; however, cationization can increase their uptake by adsorptive-mediated endocytosis and transcytosis. (f) The efflux pump expulses the drugs from the endothelial cells to the blood. Delivery of nanoparticles across the brain endothelium enters mainly via routes (d) and (e). (g) Cytochrome P450 enzymes. Adapted from Abbott NJ, Patabendige AA, Dolman DE, Yusof SR, Begley DJ. Structure and function of the blood-brain barrier. Neurobiol Dis. 2010;37(I):13-25. ${ }^{22}$

Abbreviations: BBB, blood-brain barrier; CNS, central nervous system.

this critical process along the "glymphatic system" in the CNS, which facilitates a tertiary circulation critical for waste removal (Figure 2). ${ }^{29}$ The exchange of cerebrospinal fluid and interstitial fluid throughout the glymphatic system is in part dependent on the pulsatility of cerebral arteries ${ }^{30}$ and is most pronounced during sleep. ${ }^{31}$

In the context of this review, the glymphatic system can be involved in the clearance of nanoparticles from the brain

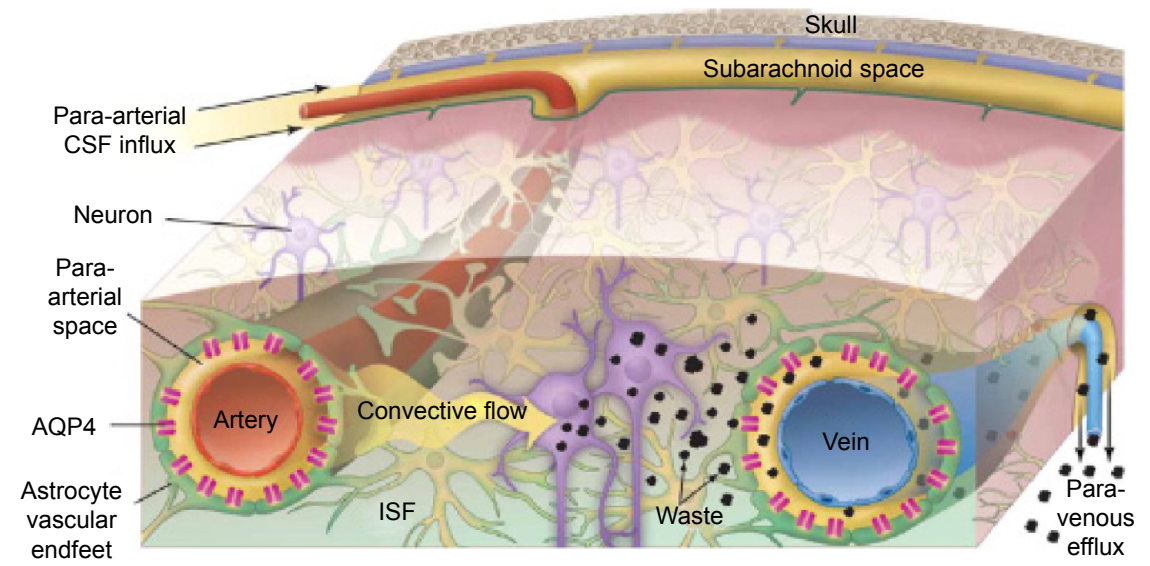

Figure 2 Schematic outline of the glymphatic system.

Notes: Convective glymphatic fluxes of cerebrospinal fluid and interstitial fluid propel the waste products of neuron metabolism into the para-venous space, from which they are directed into lymphatic vessels and ultimately return to the general circulation for clearance by the kidney and liver. From Nedergaard M. Neuroscience. Garbage truck of the brain. Science. 20I3;340(6I 140): 1529-1530. Reprinted with permission from AAAS. ${ }^{28}$

Abbreviations: CSF, cerebrospinal fluid; ISF, interstitial fluid. 
parenchyma. However, to the best of our knowledge, no studies have previously investigated this topic.

\section{Physiological mechanisms to cross the BBB}

Despite the strict insulation of the CNS by the BBB, which limits the passage of unspecific molecules into the brain, various mechanisms are present by which essential molecules and nutrients are supplied to the brain to ensure the correct function of this organ and to maintain the properties and functions of the BBB. Lipophilic substances or small gaseous molecules can spread through the lipid membranes via a nonsaturable passive mechanism (Figure 1, mechanism c). Hydrophilic molecules can cross via saturable mechanisms that are mainly energy requiring (an active mechanism). The saturable transport to cross the BBB can be divided into different mechanisms: carrier-mediated transport (mechanism $b$, Figure 1), adsorptive-mediated transcytosis (AMT; mechanism e, Figure 1), and receptor-mediated transcytosis (RMT; mechanism d, Figure 1). Moreover, a route to cross the BBB that is well established for viruses such as Cryptococcus and human immunodeficiency virus (HIV) has recently been identified and relies on immune cells such as monocytes and macrophages to cross the BBB. This mechanism can be used for nanoparticles.

\section{Mechanisms for hydrophilic small and large molecules and for nanoparticles}

Carrier-mediated transport is driven by highly specialized proteins that supply nutrients to the brain. This mechanism is effective for different types of small molecules such as glucose, tyrosine, ascorbic acid, linear opioid peptide, cyclic opioid peptide, dendrimers, and glutathione. However, AMT and RMT, which are vesicle-based mechanisms, are effective for large molecules and nanoparticles (Figure 1B). We focus our attention on these two last mechanisms in which peptides, proteins, and AuNPs are involved.

\section{Adsorptive-mediated transcytosis}

AMT is an energy-dependent mechanism without any membrane receptors and is used by cell-penetrating peptides (CPPs) and cationic molecules to cross the BBB. The process begins with an interaction of the cationic group of a compound with the negative charges on the plasma membrane (sulfated proteoglycans). ${ }^{32}$ This interaction leads to endocytosis, which can lead to transcytosis. Several drugs have been described that use this mechanism to reach the CNS. ${ }^{33,34}$ Nevertheless, select endogenous molecules also use this mechanism such as immunoglobulin $\mathrm{G}$ and albumin.
The main drawback of the adsorptive process is a lack of specificity to cross the BBB and that this process could occur in any other organ. Thus, the use of this process in drug delivery must overcome the challenge of distribution to a target organ. However, an important point to be considered is the toxicity and immunogenicity of cationic proteins and peptides because several studies have reported the occurrence of toxicity and tissue inflammation..$^{35}$

\section{Receptor-mediated transcytosis}

Another transport system is RMT. This mechanism is highly specific and uptakes macromolecules from the luminal side of the brain endothelial cells and releases them to the abluminal side. This process provides the selective uptake of molecules that are necessary for the correct function of the brain. These large molecules are taken up by endothelial cells, which express receptors to many different ligands, for example, insulin, transferrin, leptin, and apolipoprotein. The entire process consists first of receptor-ligand recognition at the luminal side and then endosome formation, which transports the ligand across the endothelial cell, and exocytosis at the other side of the membrane (the abluminal side). RMT has been widely studied in brain drug delivery ${ }^{36}$ because this system can provide a high effectiveness in the targeting strategy of many compounds that are not able to reach the brain by themselves. One approach is known as the molecular Trojan horse, in which the drug or biological compound is modified through conjugation to a ligand, thereby covering the intrinsic properties and tricking the BBB.

RMT has displayed an effective transport of large molecules, polymeric complexes, liposomes, and nanoparticles to the brain. ${ }^{37,38}$ In both carrier-mediated transcytosis and RMT, the polarized expression of select receptors in the luminal face generates a selective mechanism of transport for the input of polar nutrients, ions, and macromolecules. Many of these receptors have been used as a target in certain drug delivery systems to the brain. By contrast, AMT is based on endocytosis upon the binding of highly charged cationic compounds to the plasma membrane.

An important factor in drug delivery is that the BBB is both a physical barrier and a metabolic barrier that contains several enzymes. Specifically, the cytochrome P450 enzyme system has been detected in the brain, primarily in the endothelial cells of the brain microvessels. ${ }^{39}$ This enzymatic system is one of the most effective methods whereby the organism metabolizes xenobiotics, and in the case of crossing the $\mathrm{BBB}$, the drugs can be metabolized, diminishing the concentration in the brain parenchyma. 
On the other hand, the immune system could play an important role in crossing the BBB. Perivascular macrophages, which reside on the parenchymal side of endothelial cells close to the astrocyte endfeet, originated from circulating phagocytes such as monocytes and have shown a remarkable capability to cross an intact BBB with $80 \%$ turnover in 3 months. ${ }^{40}$ Notably, monocytes/macrophages have been suggested as being utilized by pathogens as a vehicle to enter the CNS. ${ }^{41}$

\section{Inhibition of efflux systems to enhance brain delivery}

The BBB has drug efflux transporters to protect the CNS from toxic xenobiotics, but these transporters prevent the entrance of drugs to the brain. These transporters are transmembrane proteins that can remove diverse types of drugs from brain endothelial cells using energy from ATP. ${ }^{42}$ Some of these transporters include P-glycoprotein (P-gp; ABCB1), breast cancer resistance proteins (ABCG2), and multidrug resistance proteins $1,2,4$, and 5 ( $\mathrm{ABC}$ family). Of the transporters listed, P-gp is the most studied efflux transporter in the attempt to find new approaches to improve drug delivery to the CNS that could also be applied to AuNPs. The main strategy to reach this goal consists of the inhibition of this efflux transporter. The accumulation of drugs and substrates by the inhibition of efflux transporters has been shown to improve when they are co-administered with a pharmacological inhibitor of P-gp. ${ }^{43}$

As was reviewed by Alyautdin et $\mathrm{a}^{44}$ the expression of transport systems that pump medicinal preparations from endothelial cells restricts the accumulation of many compounds in the brain. $\mathrm{ABC}$ transport systems provide effective excretion of lipophilic compounds that penetrate the cytoplasm of the endothelial cell through the apical membrane. Moreover, the activity of $\mathrm{ABC}$ transport systems, particularly P-gp, may be increased under pathological conditions. Resistance to antiepileptic remedies may be explained by the increased activity of P-gp because it can possibly transport phenytoin, levetiracetam, lamotrigine, and phenobarbital. The expression of pumping-out transport systems limits the usage of many effective antitumor preparations in the treatment of brain malignancies. Thus, paclitaxel, a taxane group preparation that was effective on tumor cells in vitro, is not effective in the treatment of brain tumors because of the P-gp activity in apical membranes of endothelial cells. The simultaneous administration of paclitaxel and an inhibitor of P-gp, PSC833, caused a significant increase in BBB permeability of paclitaxel. In transgenic ( $\mathrm{Tg}$ ) mice lacking
P-gp, the concentration of vincristine and ivermectin in the brain was 80 - to 100 -fold higher than that in normal mice. The administration of $A B C$ transporter substrates combined with efflux inhibitors has been employed to increase the permeability of endothelial cells. Thus, modulators of P-gp activity, such as verapamil and diltiazem, are used to increase the brain delivery of viral protease inhibitors, antitumor substances (paclitaxel), and the antifungal agent itraconazole. ${ }^{44}$

The other class of these pharmacological modulators is the well-known Pluronic ${ }^{\circledR}$ poloxamers, which are able to inhibit the P-gp efflux pump, a property discovered at the Kabanov laboratory by Batrakova et al. ${ }^{45}$ Pluronic ${ }^{\circledR}$ poloxamers consist of hydrophilic ethylene oxide and hydrophobic propylene oxide blocks, which form a tri-block structure, yielding both amphiphilic and surfactant properties. Pluronic ${ }^{\circledR} \mathrm{P} 85$ has been widely studied because of its capacity to enhance the BBB permeability of several types of drugs (such as taxol, doxorubicin, valproic acid, etoposide, 3-azido-3-deoxythymidine, and loperamide) in in vitro studies using a bovine brain microvessel endothelial cell monolayer. ${ }^{46}$ The advantage of Pluronic ${ }^{\circledR}$ P85 over P-gp results from two mechanisms of action. One mechanism directly inhibits P-gp activity by an allosteric interaction, and the second mechanism involves an indirect inhibition through ATP depletion. ${ }^{47}$ Additionally, this copolymer can interact with the cell membrane, resulting in "membrane fluidization" ${ }^{48}$ The inhibition of P-gp, which enhances the penetration of a number of useful drugs, would also open the BBB to potentially toxic substances. Whereas such a risk can be acceptable for the treatment of patients with cancer, the risks associated with long-term therapy required to treat patients with chronic CNS diseases should be carefully weighed. ${ }^{44}$ Although the mechanism of inhibition of the efflux system for the delivery of small drugs to the CNS is well documented, this concept has not been investigated for the delivery of nanoparticles.

\section{Peptide, protein, and nanoparticle mechanisms used to cross the BBB}

Peptides can cross the BBB via various mechanisms. Passive diffusion for peptides is limited, whereas the use of carrier systems expressed at the BBB is a useful strategy to deliver peptides to the brain. Carrier-mediated transporter is driven by highly specialized proteins that supply nutrients to the brain. This mechanism is effective for various types of small molecules such as glucose, tyrosine, ascorbic acid, linear opioid peptides, cyclic opioid peptides, dendrimers, and glutathione. However, for carrier-mediated 
transporters, specific chemical groups must be bound to render them as substrates for endogen carriers, for example, by glycosylation of the peptide to enable transport through the GLT-1 receptors. ${ }^{49,50}$ AMT and RMT are mechanisms by which several peptides are transported across the BBB. Binding a peptide with affinity for the membrane or to a specific membrane receptor on the cell surface can trigger endocytosis. AMT and RMT, which are vesicle-based mechanisms, are effective for large molecules and nanoparticles (Figure 1). We focus our attention on these two mechanisms which can be utilized by peptides, proteins, and AuNPs.

\section{AMT as a mechanism used to permeate the BBB by peptides and proteins}

AMT, an energy-dependent mechanism that does not use membrane receptors, is used by the so-called CPPs, which are peptides that facilitate the cellular uptake of various molecular cargoes (from nanosized particles to small chemical molecules and large fragments of DNA) and cationic molecules that cross the BBB. The CPPs share a common feature: the ability to interact with the lipid membranes. ${ }^{51,52}$ The internalization process begins with the interaction of the cationic group of a compound (cationized albumin, for example) with the negative charges on the plasma membrane (sulfated proteoglycans). ${ }^{32}$ This interaction follows the endocytosis process, leading to transcytosis. Examples include the transactivator of transcription (TAT), penetratin, and the SynB vectors (family of vectors derived from the antimicrobial peptide protegrin 1). A number of other CPPs are the product of engineering efforts, for example, the homoarginine vectors, the model amphipathic peptide, transportan, and other chimeric peptides such as signal-based peptide and the fusion sequence-based peptide. ${ }^{53,54}$ Several species have been delivered into cells using CPPs as carriers such as nanoparticles, liposomes, and fragments of DNA. ${ }^{55}$ This mechanism has been described for different molecules that reach the CNS such as micro 1-specific opioid peptide, ${ }^{32-34}$ and select endogenous molecules, such as immunoglobulin $\mathrm{G}$ and albumin, also use this mechanism. ${ }^{35,56}$ In an AMT-based delivery strategy, CPPs with the TAT sequence, penetratin, D-penetratin, SynB, pegelin, and the heptapeptide Gly-LPhe-D-Thr-Gly-L-Phe-L-Leu-L-Ser $(O$ - $\beta$-D-glucose)-CONH (g7) are used as vectors for different cargoes. For example, the TAT sequence, which is an arginine-rich CPP originated from HIV type-I, contains arginines that enable interaction with negatively charged membranes. The guanidinium group of the arginine is required for peptide uptake and is more potent than other cations. ${ }^{57}$ This mechanism is independent of cell receptors and temperature.

\section{RMT as a mechanism used to permeate the BBB by peptides and proteins}

Different strategies are used for the recognition of various endothelial cell receptors in the BBB such as the lowdensity lipoprotein receptor-related protein, the low-density lipoprotein receptor, the transferrin receptor, and the leptin receptor, which are selectively recognized by the peptides angiopep and VH0411, the antibody OX26, and leptin, respectively. ${ }^{58}$

RMT and AMT comprise the potential routes across the BBB for the Trojan horse approach. Select examples of these strategies include erythropoietin attached to a monoclonal antibody against the mouse transferrin receptor, which is used for neuroprotection in strokes, ${ }^{53}$ carbon nanotubes conjugated with peptide angiopep-2, ${ }^{59}$ cationic solid lipid nanoparticles (formed from a mixture of oppositely charged surfactants) grafted with 5 -HT-moduline, ${ }^{60}$ lactoferrin conjugated to $\beta$-cyclodextrin, ${ }^{61}$ and liposomal nanoparticles modified with apolipoprotein-E (ApoE). ${ }^{54}$

Limitations of using peptides as drug carriers include their stability in the blood, saturation of AMT or RMT, and competition with natural substrates. To overcome these issues, more stable $N$-methylated peptides that can enter the BBB can be used, as discussed by Malakoutikhah et al. ${ }^{62}$ $N$-methylated peptides can enter the brain by nonsaturable passive diffusion and shuttle small drugs to this organ. Giralt and coworkers recently found that small cyclic $N$-methylated and NMePhe-rich peptides can carry small drugs, such as dopamine, baicalin, levodopa, Nip, gamma-aminobutyric acid, and 5-aminolevulinic acid, in in vitro BBB models such as the parallel artificial membrane permeability assay and bovine brain microvessel endothelial cells. ${ }^{63,64}$

\section{Permeation of the BBB by AuNPs}

A size-dependent distribution of AuNPs in organs in vivo has been reported in various studies. ${ }^{65-73}$ Administration of GNSs $(10 \mathrm{~nm}$ or $15 \mathrm{~nm})$ results in the widespread organ distribution (in the liver and spleen in high concentrations, and in the lungs, kidneys, heart, and brain in lower concentrations). We demonstrated that GNSs (12 nm in diameter) administered intraperitoneally in mice bioaccumulated in the brain depending on the administered dose. ${ }^{65}$ The percentage encountered in the brain with respect to the doses remains too low $(0.01 \% \mathrm{ID} / \mathrm{g}$ or lower). Whether AuNPs are present in the brain parenchyma or in the endothelial cells must be determined. Thus, Chen et al 
investigated the microscopic distribution of AuNPs in the hippocampus using coherent anti-Stokes Raman scattering microscopy and transmission electron microscopy. ${ }^{73}$

In the literature, different strategies are described to increase the penetration of nanoparticles into the CNS. In physiological conditions, the penetration of AuNPs is too low; however, after different but not innocuous treatments or under pathological conditions, the permeability can be enhanced. One example is the enhanced delivery of AuNPs with therapeutic potential into the brain using magnetic resonance imaging (MRI)-guided focused ultrasound. When using focused ultrasound, the BBB permeability was transiently increased, allowing the delivery of AuNPs. ${ }^{74}$

Under pathological conditions, such as brain tumors or diseases related to inflammation, a disruption of the selective properties of the vascular endothelia is present, which could be useful for the selective accumulation (passive targeting by the ERP effect) of AuNPs in the affected tissue. As an example, we mention the study by Hainfeld et $\mathrm{al}^{75}$ that, for imaging and therapy purposes (theranostics), intravenously injected AuNPs into a mouse with lethal intracerebral malignant glioma for X-ray imaging and enhanced radiotherapy. This study reported that the gold uptake enabled the highresolution computed tomography for tumor imaging, and gold radiation enhancement significantly improved the longterm survival compared with radiotherapy alone. ${ }^{75}$ However, in such pathological conditions, the permeation of the BBB is not typical because its anatomical structure and physiology could be completely altered.

\section{What impedes or assists AuNPs in permeating the $B B B$ ?}

When nanoparticles are administered, various plasma proteins bind to their surface, forming the so-called protein corona. ${ }^{76-81}$ These capped nanoparticles can then be recognized by the macrophage cell surface and be internalized, leading to a significant loss of the nanoparticles from circulation. A portion of the serum proteins that bind and cap the nanoparticles is termed opsonins. The nanoparticles capped with these proteins can be recognized and captured by the macrophages, contributing to the loss of the majority of the ID because of the retention by the RES. ${ }^{82}$ Modification of colloidal particles with PEG can increase their half-life in the blood.

However, the capping of AuNPs with endogenous proteins could support BBB penetration by RMT or AMT. Reddy and Venkateswarlu and Kreuter proposed that nanoparticles could cross the BBB via a low-density lipoprotein receptor on endothelial cells mediated by the adsorption of apolipoprotein-B and/or ApoE from the blood to the nanoparticles. ${ }^{83,84}$ In addition, RMT mechanisms allow for the delivery of particles, such as transferrin and insulin receptors, to the brain. ${ }^{85,86}$

As discussed by Kreuter ${ }^{87}$ other mechanisms for nanoparticles to cross the $\mathrm{BBB}$ under physiological conditions can include the inhibition of the P-gp efflux system using polysorbate 80 or pluronic acids, ${ }^{88}$ the increased retention of nanoparticles in the BBB capillaries combined with adsorption on the capillary walls, the presence of a surfactant that fluidizes the membrane, the temporal opening of tight junctions between the brain blood vessel endothelial cells, a general toxic effect in the BBB, or the combination of all of these mechanisms. ${ }^{87}$

\section{Peptides and proteins for the delivery of nanoparticles and drugs to the CNS}

In the next sections, we discuss the preclinical applications of peptides or proteins as carriers of nanoparticles for the delivery of cargoes to the CNS and to address nanoparticles or drugs for potential treatments of CNS disorders. Peptides were used mainly to enhance the delivery of polymeric nanoparticles and liposomes that contain active drugs; ${ }^{89-109}$ however, select examples of the use of peptides for the delivery of metal nanoparticles to the CNS have been noted. In the next section, we focus on the conjugation of peptides to metal nanoparticles to enhance their permeation through the BBB.

\section{AuNPs can be conjugated with peptides or proteins to enhance their permeation through the BBB}

To the best of our knowledge, limited reports cover the use of peptides or proteins to improve the permeation of metal nanoparticles through the BBB (Table 1). Table 1 summarizes the preclinical uses of peptides and proteins for the delivery of metal nanoparticles of different compositions that include various cargoes.

Our group improved the brain delivery of AuNPs by conjugation with the amphipathic peptide CLPFFD. ${ }^{110,111}$ This peptide is a $\beta$-breaker peptide designed by Soto et $\mathrm{al}^{112}$ (which is based on the original sequence of $\beta$-amyloid), and contains a Cys added to the extreme N-terminal portion of the peptide for the chemisorption to the gold surface resulting in the conjugate AuNP-CLPFFD. This conjugate is used for the microwave destruction of $\beta$-amyloid toxic aggregates. An enhancement from approximately $0.01 \%$ $\mathrm{ID} / \mathrm{g}$ to approximately $0.05 \% \mathrm{ID} / \mathrm{g}$ in the brain tissue was observed for AuNP-CLPFFD (with respect to AuNPs). The improvement in the delivery to the brain could be attributed 
Table I Preclinical uses of peptides and proteins in the delivery of metal nanoparticles and their potential applications

\begin{tabular}{|c|c|c|c|c|}
\hline Metal nanoparticles & Peptide used & Therapeutic target & Year & Authors \\
\hline GNS & CLPFFD & Overcome the BBB, in vivo & 2010 & Guerrero et al $\left.\right|^{110}$ \\
\hline GNS & CLPFFD-THR & $\begin{array}{l}\text { Overcome the BBB } \\
\text { for neurodegenerative disorders }\end{array}$ & 2012 & Prades et $\mathrm{al}^{115}$ \\
\hline GNS & CLPFFD & Overcome the BBB, in vivo & 2012 & Guerrero et al ${ }^{\prime \prime \prime}$ \\
\hline $\begin{array}{l}\text { Spherical silica cores } \\
\text { and thin gold shells }\end{array}$ & VEGF & Glioma potential treatment & 2012 & Day et $\mathrm{al}^{116}$ \\
\hline $\begin{array}{l}\text { CdSe/ZnS core-shell } \\
\text { quantum dots }\end{array}$ & Palm l & $\begin{array}{l}\text { Delivery of neurotherapeutics } \\
\text { to neurons }\end{array}$ & 2012 & Walters et $\mathrm{al}^{117}$ \\
\hline Iron oxide & Fibrin $\gamma 377-395$ peptide & Inhibition of microglial cells & 2013 & Glat et al $\left.\right|^{118}$ \\
\hline $\begin{array}{l}\text { PEG-superparamagnetic } \\
\text { iron oxide }\end{array}$ & $A \beta I-42$ & Detection of amyloid plaques in vivo & 2013 & Wadghiri et al ${ }^{120}$ \\
\hline PEG-GNS & $\begin{array}{l}\text { Fragment of the neural cell } \\
\text { adhesion molecule LI }\end{array}$ & $\begin{array}{l}\text { Drug delivery platform } \\
\text { for neurons }\end{array}$ & 2013 & Schulz et al ${ }^{119}$ \\
\hline GNSs & KRGD-PEGSH & Photoacoustic detection of glioma & 2011 & Lu et al ${ }^{121}$ \\
\hline Gold glyconanoparticles & $\begin{array}{l}\text { CII-Glycopep, } \\
\text { CII-Enk peptide }\end{array}$ & $\begin{array}{l}\text { Overcome the BBB, in vivo distribution, } \\
\text { PET reporter }\end{array}$ & 2014 & Frigell et a $\left.\right|^{122}$ \\
\hline GNS & Insulin & Improve brain delivery of AuNPs & 2014 & Shilo et al ${ }^{125}$ \\
\hline GNS & Albumin or ApoE & Biodistribution studies & 2014 & Schäffler et al ${ }^{124}$ \\
\hline
\end{tabular}

Abbreviations: GNS, gold nanosphere; BBB, blood-brain barrier; VEGF, vascular endothelial growth factor; PEG, polyethylene glycol; PET, positron emission tomography; AuNPs, gold nanoparticles; ApoE, apolipoprotein-E.

to an interaction of the conjugate with the receptor because of the advanced glycation end products, which binds $\beta$-amyloid and mediates transcytosis across the BBB. ${ }^{113,114}$ Notably, the major percentage of the ID of AuNPs is eliminated by biliary and urinary excretion and is accumulated in the liver and spleen, as demonstrated in in vivo experiments using positron emission tomography (PET) by our group. ${ }^{111}$ The accumulation in the liver and spleen is a crucial issue that can limit the transport of nanoparticles to the CNS and their clinical applications.
Moreover, to enhance the permeation of the BBB of AuNPCLPFFD, we incorporated the peptide THRPPMWSPVWP (which recognizes the transferrin receptor [Figure 3] favoring the RMT present in the microvascular endothelial cells of the $\mathrm{BBB}$ ) to the CLPFFD sequence, causing an increase in the permeability of the conjugate in the brain as was determined by analyzing the gold content by neutron activation and by transmission electron microscopy. ${ }^{115}$ The sequence THRPPMWSPVWP interacts with the transferrin receptor present in the microvascular endothelial cells of the BBB, causing

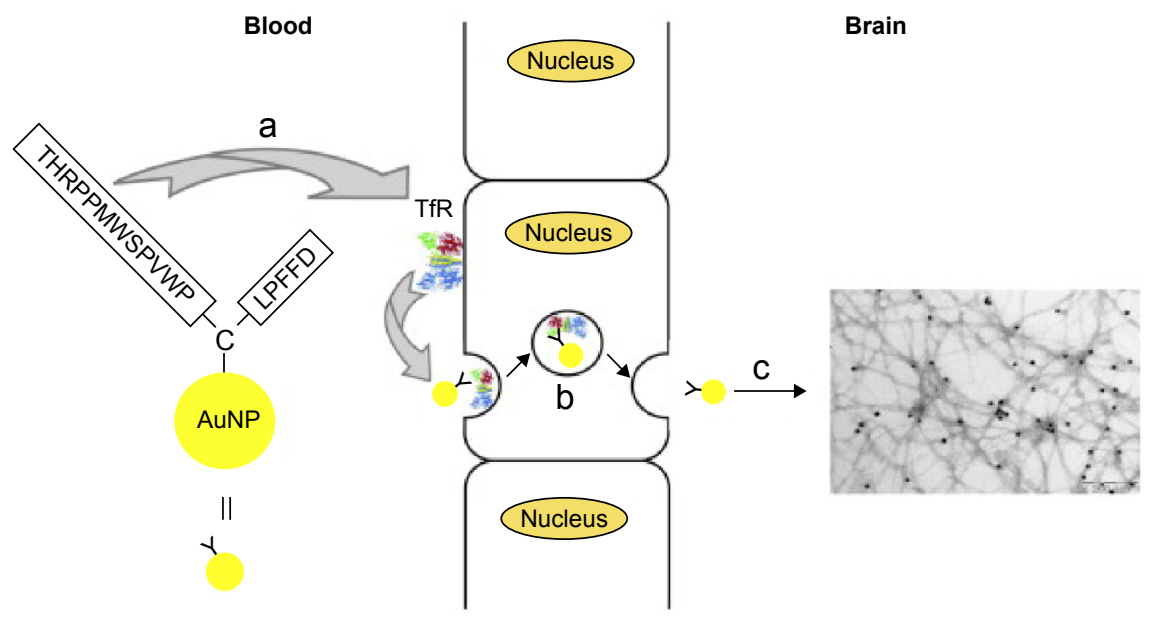

Figure 3 Scheme to rationalize the design of the conjugate AuNP-THR-LPFFD.

Notes: (a) The peptide THR-CLPFFD anchored to the AuNP. This peptide contains the THR sequence, which recognizes the transferrin receptor, and LPFFD, which recognizes $A \beta$ aggregates. (b) Transport of the endocytic vesicle through the endothelial cells of the $B B B$. (c) Recognition and binding of the conjugate to $A \beta$ aggregates inside the CNS. The transferrin receptor is abbreviated as TfR. Reprinted from Prades R, Guerrero S, Araya E, et al. Delivery of gold nanoparticles to the brain by conjugation with a peptide that recognizes the transferrin receptor. Biomaterials. 2012;33(29):7194-7205, with permission from Elsevier. ${ }^{115}$

Abbreviations: AuNP, gold nanoparticle; BBB, blood-brain barrier; CNS, central nervous system. 
an increase in the permeability of the conjugate AuNP-peptide in brain, as shown by in vitro and in vivo experiments. ${ }^{115}$

Day et $\mathrm{l}^{116}$ used silica nanoparticles coated with a thin layer of gold to generate photothermal therapy in a model of murine glioma. These nanoparticles were functionalized with vascular endothelial growth factor to recognize positive cells for vascular endothelial growth factor receptor 2 . The in vitro results showed that the proposed nanosystem bound to the cell population of interest, and in vivo experiments were successful in inducing vascular disruption after laser exposure in the orthotopic murine glioma model used without damaging healthy regions of the brain (Table 1). ${ }^{116}$

Walters et al used quantum dots with a polyampholyte coating, obtaining a remarkable tropism for neurons, evaluated in hippocampal slice cultures of adult rats and discriminating among other cell populations (astrocytes, oligodendrocytes, or microglia). ${ }^{117}$ In a different study, Glat et al directed iron oxide nanoparticles to another cell population, microglia, achieving inactivation in vivo in a mouse model of Alzheimer's disease. In this work, iron oxide nanoparticles were modified with fibrin peptide $\gamma 377-395$, decreasing the number of activated microglia compared to the administration of free peptides (Table 1). ${ }^{118}$

In another approach, Schulz et $\mathrm{al}^{119}$ used AuNP functionalized with a fragment of peptide L1, which maintains the minimum recognition domain and function. The peptide L1 promotes regeneration in models of acute and chronic damage to the adult CNS. In in vitro experiments testing this nanosystem, neurite outgrowth was observed, and an increased survival of neurons of the CNS and peripheral nervous system was noted.

On the other hand, the conjugation of ultrasmall superparamagnetic iron oxide (USPIO) to A $\beta 1-42$ allows the detection of amyloid plaques in vivo using magnetic resonance microimaging $(\mathrm{mMRI})$ after intravenous femoral injection in a Tg mice model of Alzheimer's disease. ${ }^{120}$ The amyloid plaques were detected by $\mathrm{T} 2 *$-weighted mMRI (Figure 4) that were confirmed with matched histological sections. Interestingly, the probed USPIO-PEG-A $\beta 1-42$ could be used for amyloid plaque detection in vivo by intravenous injection without the need to co-inject an agent which increases permeability of the BBB.

In preclinical cancer treatments, hollow GNSs functionalized with the c(KRGDf)-PEG-SH sequence are used for photoacoustic tomography detection of glioma and angiogenic blood vessels in a mouse model. ${ }^{121}$ In addition, by conjugating neuropeptides to glucose-coated AuNPs (2 nm) labeled with ${ }^{68} \mathrm{Ga}$, the BBB permeability of AuNPs ${ }^{122}$ could be explored using PET, and the uptake of the neuroactive peptides could be improved (Figure 5). A NOTA ligand was the chelating agent for the ${ }^{68} \mathrm{Ga}$, and two related opioid peptides were used as targeting ligands to improve BBB permeation. The biodistribution of ${ }^{68} \mathrm{Ga}$-AuNPs varies depending on the ligands because AuNPs with the identical gold core size exhibit
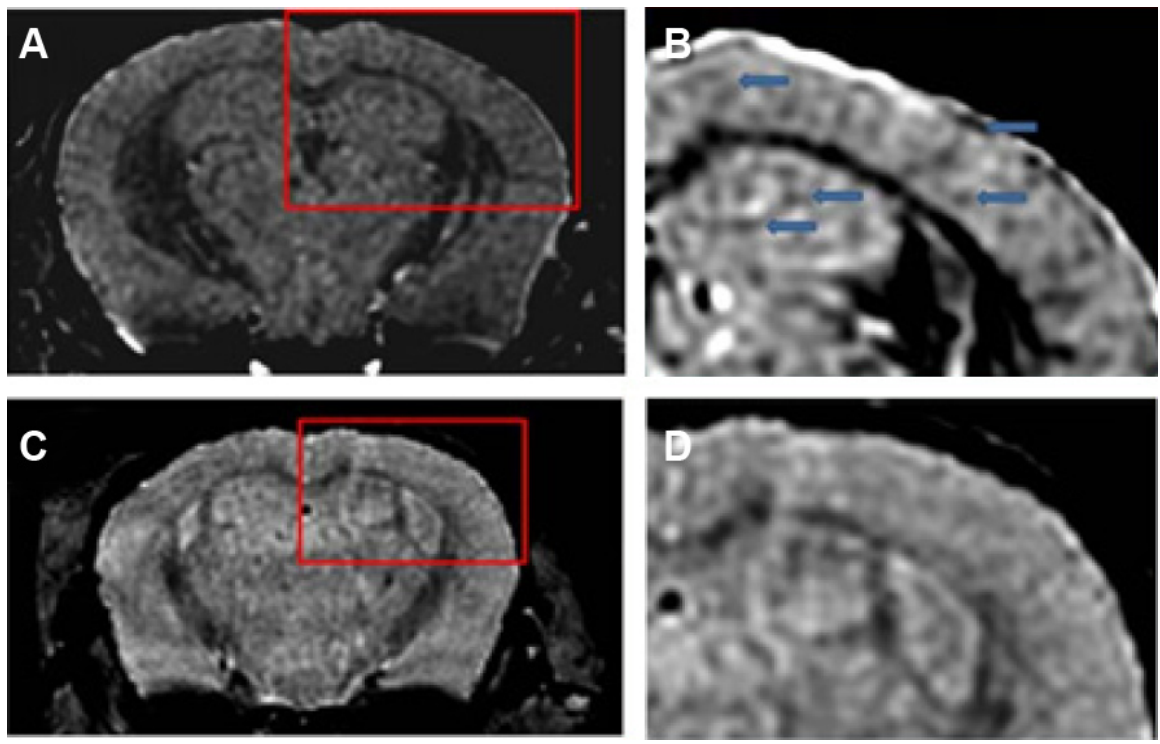

Figure 4 Amyloid plaques detected with in vivo mMRI after intravenous femoral injection of USPIO-PEG-A $\beta$ I-42.

Notes: (A) In vivo T2*-weighted mMRI images of a I4-month-old APP/PSI transgenic mouse. (B) A higher magnification of the area in the red box shown in (A). Arrowheads highlight some amyloid plaques detected by mMRI. (C) In vivo mMRI of a 16-month-old wild-type mouse after intravenous femoral injection of USPIO-PEG-A 3 I-42. (D) A higher magnification of the area in the red box shown in (C). Adapted with permission from Wadghiri YZ, Li J, Wang J, et al. Detection of amyloid plaques targeted by bifunctional USPIO in Alzheimer's disease transgenic mice using magnetic resonance microimaging. PLoS One. 2013;8(2):e57097. ${ }^{120}$

Abbreviations: mMRI, magnetic resonance microimaging; USPIO, ultrasmall superparamagnetic iron oxide; PEG, polyethylene glycol. 


\section{New nanoformulation}

Neuropeptide functionalization

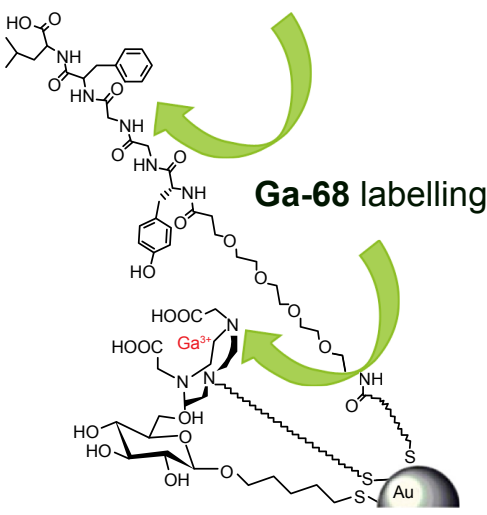

Glucose-coated AuNP

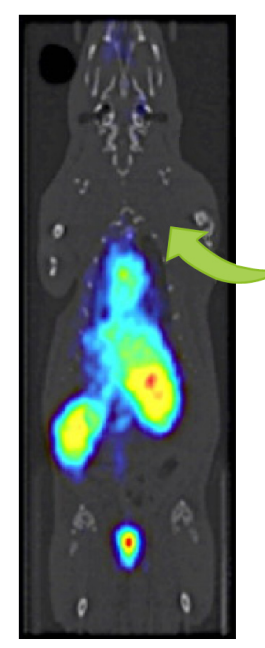

PET/CT
In vivo studies

Whole-body PET biodistribution study

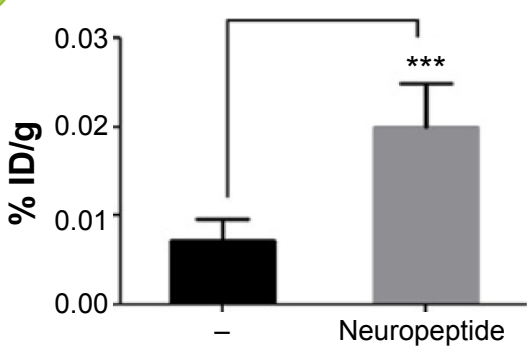

Improved brain uptake

Figure 5 The increment of the uptake of AuNPs into the brain.

Notes: Left: The conjugate peptide-AuNPs labeled with ${ }^{68} \mathrm{Ga}$. Right: The increment of the uptake of AuNPs into the brain. ${ }^{* * *} P<0.00 \mathrm{I}$, significantly different from no targeted AuNP. Adapted with permission from Frigell J, Garcia I, Gomez-Vallejo V, Llop J, Penades S. 68Ga-labeled gold glyconanoparticles for exploring blood-brain barrier permeability: preparation, biodistribution studies, and improved brain uptake via neuropeptide conjugation. J Am Chem Soc. 2014;136(I):449-457, Copyright 20I4 American Chemical Society. ${ }^{122}$ Abbreviations: AuNPs, gold nanoparticles; PET/CT, positron emission tomography/computed tomography.

different distribution profiles. The targeted ${ }^{68} \mathrm{Ga}-\mathrm{AuNPs}$ improved BBB permeation nearly threefold $(0.020 \% \mathrm{ID} / \mathrm{g})$ compared with the non-targeted AuNPs $(0.0073 \%$ ID/g), as measured by dissection and tissue counting.

It is important to mention that the entrance of AuNPs administered intravenously is very low with respect to small molecules. As an example can be mentioned the case of novel ${ }^{18} \mathrm{~F}$-labeled benzofuran derivatives for PET imaging of $\beta$-amyloid plaques in Alzheimer's brains. In this case, $2 \%-3 \% \mathrm{ID} / \mathrm{g}$ (administered systemically in mouse) was observed to enter the brain. ${ }^{123}$

Other studies related to the functionalization of AuNPs are found in the literature. Sousa et al functionalized AuNPs with cationized human serum albumin to induce AMT through the BBB. ${ }^{9}$ This study followed the biodistribution with near-infrared time-domain imaging in mice up to 7 days after the intravenous injection of the nanoparticles, and observed that the particles mainly accumulate in the hippocampus, thalamus, hypothalamus, and the cerebral cortex. In addition, Schäffler et al capped AuNPs with albumin and observed higher accumulations in the brain. ${ }^{124}$

Shilo et al conjugated AuNPs to insulin to promote RMT. Accordingly, insulin-AuNPs and control AuNPs were injected into the tail veins of male BALB/c mice, and the gold content in the organs was analyzed using atomic absorption. The amount of insulin-AuNPs observed in mouse brains was over five times greater than that of the control, untargeted AuNPs. ${ }^{125}$

An important aspect to consider is that the structure of the peptide anchored to the nanoparticle should not be changed after it is attached to the surface of the nanoparticles when the delivery strategy involves the recognition of a receptor, as discussed in previous works. ${ }^{3,110,115,126}$ Using different techniques is relevant to determine the structure of the ligand on the AuNP surface and the number of peptides per nanoparticle, which is relevant for the interaction with the target. Various techniques have been employed for such purposes such as circular dichroism - which provides information about the secondary structure of the peptide, ${ }^{127}$ nuclear magnetic resonance - which provides information related to the structure of the molecules, ${ }^{128}$ infrared spectroscopy - which is used in the presence of functional groups ${ }^{129}$ on the surface, and surface-enhanced Raman spectroscopy. ${ }^{130,131}$ The data obtained using these techniques provide information related to the disposition of the peptides on the surface of the AuNPs. Finally, the structure of the peptide and the surface that is exposed to the biological media determine the interaction of the entity with cell membranes, triggering the entrance to the cell, as discussed previously. ${ }^{126}$

\section{Intranasal administration of AuNPs as an alternative to circumvent the BBB}

This route allows direct delivery to the brain through the movement of the drug through the trigeminal and olfactory nerves, which innervate the nasal epithelium, from the submucosal space of the nose into the cerebrospinal fluid compartment of the brain. ${ }^{132}$ This innervation is a direct connection between the outside and the brain. This process is a noninvasive method that circumvents the BBB and carries molecules to the brain. ${ }^{133}$ Thus, this route has received attention because of its great potential in CNS diseases. In the 
$\mathrm{CNS}$, several regions have no $\mathrm{BBB}$ or a $\mathrm{BBB}$ with a higher permeability, such as the olfactory nerves and the bottom of the cerebral ventricles, and drugs may be transported through these regions. This method can utilize a different type of molecule to reach the CNS and provide the advantages of avoiding the first step of metabolism and the ability to use a small dose. ${ }^{134}$ Nanoparticles could be used as a platform for CNS delivery through the intranasal route. ${ }^{135}$ As discussed by Mistry et al to date, few studies have specifically examined the direct transfer of particles, such as manganese oxide, carbon-13, iridium-19, iron (II) oxide, and titanium dioxide, from the nasal cavity to the brain. ${ }^{135}$ Wolstenholme et al administered GNSs (50 nm) intranasally and visualized them within the olfactory neurons by transmission electron microscopy. ${ }^{136}$ This study suggested that nanoparticles enter the receptor cells via an endocytic process into the axoplasm within 30 minutes. The colloidal particles moved along the axon, possibly by a mechanism related to microtubules in the cytoplasm. Within 60 minutes of application to the nasal cavity, GNSs were observed in the fila olfactoria and olfactory glomerulus, and the particles were primarily located within the mitochondria. The mechanism of such an accumulation is unclear; however, the translocation of nanoparticles into the mitochondria can lead to cellular uptake.
The published studies related to AuNPs and intranasal administrations are focused on the delivery and the physiological effects produced by the AuNPs. Joshi et al ${ }^{137}$ demonstrated that the use of AuNPs improves the brain delivery of insulin; however, the authors did not evaluate the presence of particles in the brain. In another study, after the intranasal administration of AuNPs, in Tg mice, the transient toll-like receptor 2 upregulation in the olfactory bulb was observed. However, the authors did not study the presence of AuNPs in the brain parenchyma. ${ }^{138}$ Furthermore, in that paper, the authors analyzed the internalization of nanoparticles of three morphologies, GNSs, GNRs, and urchins, coated with PEG or CTAB in microglia and primary hippocampal neurons by dark-field microscopy and by two-photon-induced luminescence. CTAB-coated GNSs and GNRs internalized readily and partly colocalized with acidic lysosomal compartments in microglia (Figure 6A). By contrast, GNSs and GNRs functionalized with PEG did not internalize in microglial cells to any significant extent. The authors also studied the effects in hippocampal neurons observing that GNRs functionalized with PEG and with CTAB decorate the dendrites of the neurons and appear to be internalized both along the neurites and within the cell body (Figure 6C). ${ }^{138}$
A
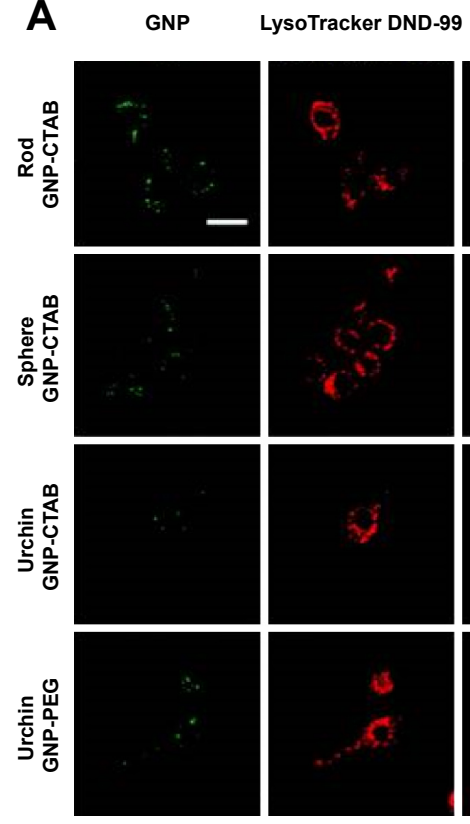

Overlay
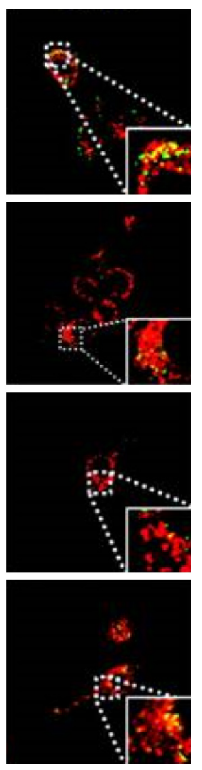

B
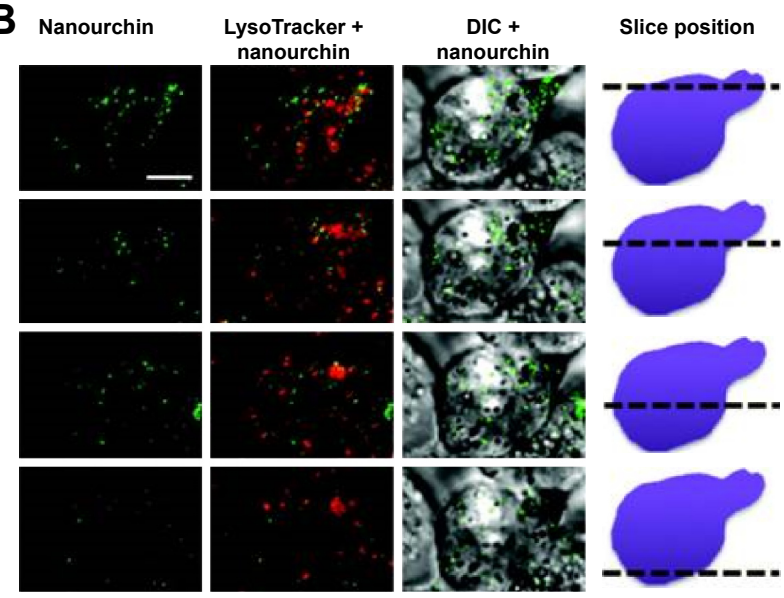

C
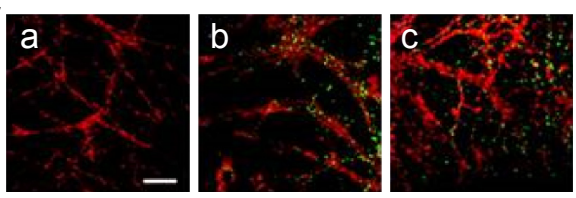

Figure 6 Two-photon luminescence imaging of internalized AuNPs in microglia and primary hippocampal neurons.

Notes: (A and B) Internalization of PEG- and CTAB-coated AuNPs in microglia. AuNPs are primarily found in the cytosol, and to a certain extent, colocalize with lysosomal compartments (indicated by enlarged inset image). Scale bar $(20 \mu \mathrm{m})$ in control overlay image is representative for all panels. (B) Internalization of urchin AuNPs. Last column of panels provides a schematic illustrating the position along the $z$ axis relative to the cell. Scale bar $(5 \mu \mathrm{m})$ in the first panel is representative for all panels. (C) Two-photon luminescence imaging of primary hippocampal neurons treated after 21 days in vitro with (b) PEG-coated and (c) CTAB-coated GNPs for up to 4 hours. Neurons were stained with MitoTracker green FM (pseudocolored red). Untreated control cells can be seen in (a). Reprinted with permission from Hutter E, Boridy S, Labrecque S, et al. Microglial response to gold nanoparticles. ACS Nano. 2010;4(5):2595-2606, copyright 2010 American Chemical Society. ${ }^{138}$

Abbreviations: AuNPs, gold nanoparticles; PEG, polyethylene glycol; CTAB, cetyl trimethylammonium bromide; GNPs, glucose-coated AuNPs. 
Kozlovskaya et al analyzed the available quantitative data on drug delivery to the brain via the nasal route and revealed the efficiency of brain drug delivery and targeting by different types of nasal-administered delivery systems. ${ }^{139}$ They concluded that the efficiency of brain delivery by the nasal route differs widely between studies. In addition, they found that the percentages of drug-targeting efficiency appear to be excessively high, at least in select studies, and the extent of brain drug delivery is likely overestimated. Therefore, the drug delivery to the brain via the intranasal route must be more exhaustively studied. Moreover, despite these advantages mentioned, a few disadvantages remain that must be overcome and represent a substantial challenge in this area. The main disadvantages of this route comprise a limitation because of low nasal absorption from a small surface area of the nasal epithelium, a highly active mucociliary clearance process, and a nasal enzymatic degradation in mucosa. ${ }^{133} \mathrm{In}$ addition, this route can cause irritation within the cavity. ${ }^{140}$

\section{Neurotoxicity of AuNPs}

Although other engineered nanoparticles have been shown to induce many neurological deficits in both in vivo and in vitro models, for AuNPs, there are limited studies related to toxicity in CNS. In relation to neurotoxicity, it is important to mention that the surface of the nanoparticles can affect the toxicity, as demonstrated by the capping of AuNPs with peptides. ${ }^{141}$ An in vitro study has been performed, evaluating the cytotoxicity of GNSs in different types of cells, including endothelial cells from the BBB. ${ }^{141}$ Three factors were studied: the presence of sodium citrate on the particle's surface, size $(10 \mathrm{~nm}, 11 \mathrm{~nm}$, and $25 \mathrm{~nm})$, and the degree of internalization of AuNPs. Cell viability and proliferation decreased after exposure to GNSs, indicating that they were concentration dependent. Additionally, the presence of a higher amount of sodium citrate on the nanoparticle surface appeared to enhance the impairment of cell viability. In addition, in vivo studies have investigated the potential toxicity of GNSs in the CNS. Chen et al evaluated cognitive damage induced by the injection of GNSs of $17 \mathrm{~nm}$ and $37 \mathrm{~nm} .^{73}$ The results indicated that AuNPs can impair learning and memory in $\mathrm{BALB} / \mathrm{c}$ mice. Brain tissue samples were collected 1 day, 14 days, and 21 days after intraperitoneal injection (with doses ranging from $0.5 \mathrm{mg} \mathrm{kg}^{-1}$ to $14.6 \mathrm{mg} \mathrm{kg}^{-1}$ ). The authors observed that $17 \mathrm{~nm}$ GNSs passed through the BBB more rapidly than did $37 \mathrm{~nm}$ GNSs. Moreover, the endocytosis of $17 \mathrm{~nm}$ GNSs into the neuronal cells in the Cornu Ammonis region of the hippocampus was associated with the reduction in cognitive ability. On the other hand, $37 \mathrm{~nm}$ GNSs did not damage cognition in mice, which is in accord with the fact that these nanoparticles were noticed in the extracellular region of the hippocampus. However, in our group, a subacute study was performed to determine the toxicity of GNSs that are able to cross the BBB and accumulate in the neural tissue without producing a toxic effect in different organs. ${ }^{65}$ However, in other studies, we determined in vitro that GNSs and GNRs functionalized with the peptide CLPFFD did not produce effects on the cell viability of neurons. ${ }^{2,110}$ A very relevant point is that to determine the potential neurotoxic effect of nanoparticles, it is necessary to increase the local concentration in the brain.

\section{Conclusion}

To enhance the delivery of AuNPs to the brain, the AuNPs can be coated with peptides or proteins that can cross the BBB using different physiological mechanisms (AMT or RMT). Peptides can also increase the colloidal stability of AuNPs and vice versa in the physiological medium. Moreover, the structure that the peptide on the surface of the nanoparticle adopts to recognize the desired receptor must be determined. Under physiological conditions, AuNPs exhibit low permeability; however, in tumor tissues or inflamed tissues, their penetration increases because of the ERP effect. This phenomenon can be used for diagnostic, therapeutic, and theranostic purposes. In the abovementioned pathological conditions, a selective accumulation of AuNPs occurs in the affected organs; however, high accumulation is also noted in the liver and spleen because of the opsonization process and retention by the RES. However, the use of inhibitors of efflux pumps can increase the retention of nanoparticles in endothelial cells and the passage of substances through the BBB. Few studies related to neurotoxicity have been reported, and most of these studies are in vitro. For this reason, drawing conclusions regarding neurotoxicity is premature, and more investigations must be performed related to this issue.

Nanoparticles capped with peptides can cross the BBB via different mechanisms, such as AMT, RMT, cell-mediated transcytosis, or a combination of methods. AuNPs have interesting properties that can be detected ex vivo and in vitro using different techniques, such as transmission electron microscopy and neutron activation, which is relevant for the elucidation and examination of the entrance mechanism. This property also facilitates the visualization of AuNPs in the brain parenchyma, which is not trivial because the quantification of gold in the brain tissue may be associated with the presence of these particles in the endothelial cells 
and not the brain parenchyma. Additionally, AuNPs have the advantage that they can be detected using in vivo techniques such as tomography, PET, and photoacoustic tomography, which is relevant for diagnostics and theranostics.

As a concluding remark, for a realistic use of AuNPs for CNS applications, the issue of nanoparticle accumulation in RES-related organs must be solved because this issue diminishes their availability to the CNS. Moreover, it is necessary to further study the neurotoxic effects of AuNPs. Finally, the use of AuNPs remains far from translation into human applications; nevertheless, analyzing the accumulated knowledge from the preclinical experiments is required for future applications.

The delivery of AuNPs to the brain can be achieved by conjugation with peptides, which is a strategy that should be investigated in greater depth. The use of different peptides that allow AMT or RMT will contribute to the permeation of AuNPs through the BBB. Ideally, the peptides used should not compete with or saturate the physiological mechanism, which could be avoided by using D-amino acids or $N$-methyl amino acids or increasing the stability of the peptide. Another important issue is to decrease the interaction with plasma proteins to diminish the opsonization process and decrease retention in the liver and spleen. This process could be avoided by capping the nanoparticles with PEG or other amphipathic polymers, which can contribute to diminishing the interaction of nanoparticles with plasma proteins and opsonization. However, the interaction of nanoparticles with certain plasma proteins, such as ApoE, can contribute to RMT.

To increase the local concentration of AuNPs and evaluate the potential neurotoxic effects of nanoparticles, experiments with stereotaxic administration in rats are currently in progress in our laboratory.

Figure 7 (right) illustrates a conjugate of AuNPs with a bifunctional PEG, which on one end is chemisorbed to the gold surface by the formation of an $\mathrm{Au}-\mathrm{S}$ bond and on the other end is associated with two different peptides, one that recognizes the receptor for RMT (half yellow circles) and another that recognizes the target (green triangles). The conjugate can also be capped with an endogenous protein such as ApoE to selectively permeate the BBB, or with a polymer such as pluronic that inhibits the efflux pumps.

Another important point is to encourage the study of the interaction of the conjugates with membranes to understand how the process of cell internalization begins.

Finally, a challenging route is to functionalize intranasal administration of AuNPs conjugated to peptides that recognize the desired target in the brain, as represented in Figure 7 (left). Moreover, a mucoadhesive polymer can be used to facilitate the administration of the conjugates of AuNPpeptides via the intranasal route.
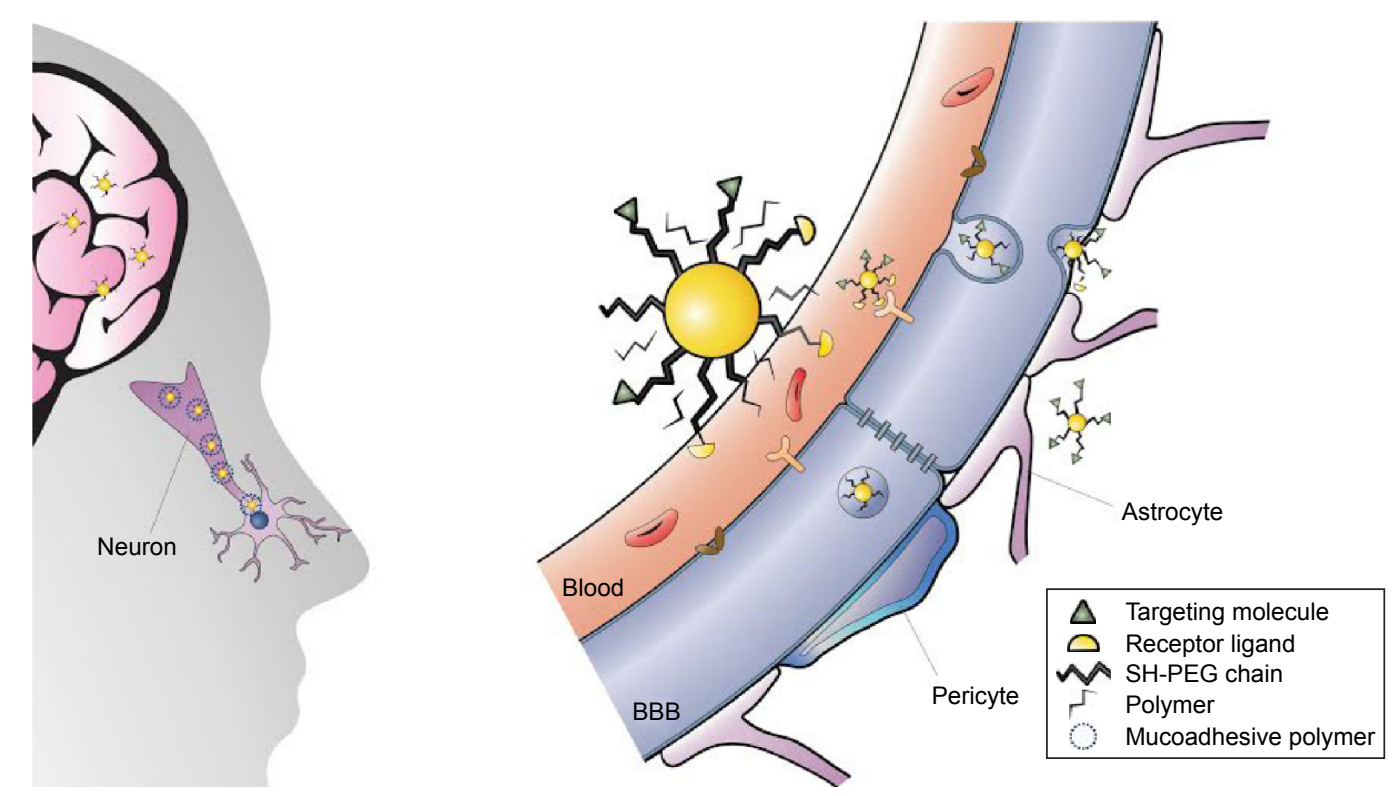

Figure 7 Strategies to enhance the delivery of AuNPs to the CNS.

Notes: Left: Intranasal administration of functionalized AuNPs that recognize the target in the brain. For the mucoadhesion of the nanoparticles to the mucosa, the nanoparticles could be capped with a polymer. Right: AuNPs capped with PEG diminish the interaction with plasma proteins, a peptide that recognizes the receptor (represented in yellow as a semicircle) for RMT and a peptide that recognizes the therapeutic target (green triangles). Note that AuNPs are not scaled with respect to the cells, brain, and organism.

Abbreviations: AuNPs, gold nanoparticles; CNS, central nervous system; PEG, polyethylene glycol; RMT, receptor-mediated transcytosis; BBB, blood-brain barrier. 


\section{Acknowledgments}

This work was supported by FONDECYT grants number 11130494 and 1130425, FONDAP grant number 15130011, UNAB DI569-14/R and MECESUP UCH-0811.

\section{Disclosure}

The authors report no conflicts of interest in this work.

\section{References}

1. Hirsch LR, Stafford RJ, Bankson JA, et al. Nanoshell-mediated nearinfrared thermal therapy of tumors under magnetic resonance guidance. Proc Natl Acad Sci U S A. 2003;100(23):13549-13554.

2. Adura C, Guerrero S, Salas E, et al. Stable conjugates of peptides with gold nanorods for biomedical applications with reduced effects on cell viability. ACS Appl Mater Interfaces. 2013;5(10):4076-4085.

3. Kogan MJ, Olmedo I, Hosta L, Guerrero AR, Cruz LJ, Albericio F. Peptides and metallic nanoparticles for biomedical applications. Nanomedicine. 2007;2(3):287-306.

4. Kohler N, Sun C, Wang J, Zhang M. Methotrexate-modified superparamagnetic nanoparticles and their intracellular uptake into human cancer cells. Langmuir. 2005;21(19):8858-8864.

5. Kogan MJ, Bastus NG, Amigo R, et al. Nanoparticle-mediated local and remote manipulation of protein aggregation. Nano Lett. 2006; 6(1):110-115.

6. Araya E, Olmedo I, Bastus N, et al. Gold nanoparticles and microwave irradiation inhibit beta-amyloid amyloidogenesis. Nanoscale Res Lett. 2008;3(11):435-443.

7. Krol S. Challenges in drug delivery to the brain: nature is against us. J Control Release. 2012;164(2):145-155.

8. Ai Tran HN, Sousa F, Moda F, et al. A novel class of potential prion drugs: preliminary in vitro and in vivo data for multilayer coated gold nanoparticles. Nanoscale. 2010;2(12):2724-2732.

9. Sousa F, Mandal S, Garrovo C, et al. Functionalized gold nanoparticles: a detailed in vivo multimodal microscopic brain distribution study. Nanoscale. 2010;2(12):2826-2834.

10. Triulzi RC, Dai Q, Zou J, et al. Photothermal ablation of amyloid aggregates by gold nanoparticles. Colloids Surf B Biointerfaces. 2008;63(2):200-208.

11. Wang YT, Lu XM, Zhu F, et al. The use of a gold nanoparticle-based adjuvant to improve the therapeutic efficacy of hNgR-Fc protein immunization in spinal cord-injured rats. Biomaterials. 2011;32(31):7988-7998.

12. Chien CC, Cheng CC, Chen HH, et al. X-ray microscopy and tomography detect the accumulation of bare and PEG-coated gold nanoparticles in normal and tumor mouse tissues. Anal Bioanal Chem. 2012;404(5):1287-1296

13. Yang X, Skrabalak SE, Li ZY, Xia Y, Wang LV. Photoacoustic tomography of a rat cerebral cortex in vivo with au nanocages as an optical contrast agent. Nano Lett. 2007;7(12):3798-3802.

14. Lu W, Huang Q, Ku G, et al. Photoacoustic imaging of living mouse brain vasculature using hollow gold nanospheres. Biomaterials. 2010; 31(9):2617-2626.

15. Wang PH, Liu HL, Hsu PH, et al. Gold-nanorod contrast-enhanced photoacoustic micro-imaging of focused-ultrasound induced blood-brainbarrier opening in a rat model. J Biomed Opt. 2012;17(6):061222.

16. Etheridge ML, Campbell SA, Erdman AG, Haynes CL, Wolf SM, McCullough J. The big picture on nanomedicine: the state of investigational and approved nanomedicine products. Nanomedicine. 2013; 9(1):1-14.

17. Libutti SK, Paciotti GF, Byrnes AA, et al. Phase I and pharmacokinetic studies of CYT-6091, a novel PEGylated colloidal gold-rhTNF nanomedicine. Clin Cancer Res. 2010;16(24):6139-6149.

18. Becker NH, Novikoff AB, Zimmerman HM. Fine structure observations of the uptake of intravenously injected peroxidase by the rat choroid plexus. J Histochem Cytochem. 1967;15(3):160-165.
19. Nabeshima S, Reese TS, Landis DM, Brightman MW. Junctions in the meninges and marginal glia. J Comp Neurol. 1975;164(2):127-169.

20. Reese TS, Karnovsky MJ. Fine structural localization of a blood-brain barrier to exogenous peroxidase. J Cell Biol. 1967;34(1):207-217.

21. Abbott NJ. Comparative physiology of the blood-brain barrier. In: Bradbury MB, editor. Physiology and Pharmacology of the Blood-Brain Barrier. Vol. 103. Berlin: Springer; 1992:371-396.

22. Abbott NJ, Patabendige AA, Dolman DE, Yusof SR, Begley DJ. Structure and function of the blood-brain barrier. Neurobiol Dis. 2010;37(1):13-25.

23. Mae M, Armulik A, Betsholtz C. Getting to know the cast - cellular interactions and signaling at the neurovascular unit. Curr Pharm Des. 2011;17(26):2750-2754.

24. Nag S. Morphology and properties of brain endothelial cells. Methods Mol Biol. 2011;686:3-47.

25. Mathiisen TM, Lehre KP, Danbolt NC, Ottersen OP. The perivascular astroglial sheath provides a complete covering of the brain microvessels: an electron microscopic 3D reconstruction. Glia. 2010;58(9):1094-1103.

26. Nagelhus EA, Ottersen OP. Physiological roles of aquaporin-4 in brain. Physiol Rev. 2013;93(4):1543-1562.

27. Iliff JJ, Wang M, Liao Y, et al. A paravascular pathway facilitates CSF flow through the brain parenchyma and the clearance of interstitial solutes, including amyloid beta. Sci Transl Med. 2012;4(147):147ra111

28. Nedergaard M. Neuroscience. Garbage truck of the brain. Science 2013;340(6140):1529-1530.

29. Verkhratsky A, Nedergaard M, Hertz L. Why are astrocytes important? Neurochem Res. 2015;40(2):389-401.

30. Iliff JJ, Wang M, Zeppenfeld DM, et al. Cerebral arterial pulsation drives paravascular CSF-interstitial fluid exchange in the murine brain. J Neurosci. 2013;33(46):18190-18199.

31. Xie L, Kang H, Xu Q, et al. Sleep drives metabolite clearance from the adult brain. Science. 2013;342(6156):373-377.

32. Pujals S, Fernandez-Carneado J, Lopez-Iglesias C, Kogan MJ, Giralt E. Mechanistic aspects of CPP-mediated intracellular drug delivery: relevance of CPP self-assembly. Biochim Biophys Acta. 2006;1758(3):264-279.

33. Deguchi Y, Naito T, Yuge T, et al. Blood-brain barrier transport of 125Ilabeled basic fibroblast growth factor. Pharm Res. 2000;17(1):63-69.

34. Deguchi Y, Miyakawa Y, Sakurada S, et al. Blood-brain barrier transport of a novel micro 1-specific opioid peptide, H-Tyr-D-Arg-Phe-betaAla-OH (TAPA). J Neurochem. 2003;84(5):1154-1161.

35. Herve F, Ghinea N, Scherrmann JM. CNS delivery via adsorptive transcytosis. AAPS J. 2008;10(3):455-472.

36. Pardridge WM. Drug and gene targeting to the brain via bloodbrain barrier receptor-mediated transport systems. Int Congr Ser. 2005;1277(0):49-62.

37. Pardridge WM. Drug targeting to the brain. Pharm Res. 2007;24(9): $1733-1744$.

38. Gabathuler R. Approaches to transport therapeutic drugs across the blood-brain barrier to treat brain diseases. Neurobiol Dis. 2010; $37(1): 48-57$

39. Decleves X, Jacob A, Yousif S, Shawahna R, Potin S, Scherrmann JM. Interplay of drug metabolizing CYP450 enzymes and ABC transporters in the blood-brain barrier. Curr Drug Metab. 2011;12(8):732-741.

40. Vass K, Hickey WF, Schmidt RE, Lassmann H. Bone marrow-derived elements in the peripheral nervous system. An immunohistochemical and ultrastructural investigation in chimeric rats. Lab Invest. 1993;69(3):275-282.

41. Gonzalez-Scarano F, Martin-Garcia J. The neuropathogenesis of AIDS. Nat Rev Immunol. 2005;5(1):69-81.

42. Dean M, Allikmets R. Complete characterization of the human ABC gene family. J Bioenerg Biomembr. 2001;33(6):475-479.

43. Choo EF, Leake B, Wandel C, et al. Pharmacological inhibition of P-glycoprotein transport enhances the distribution of HIV-1 protease inhibitors into brain and testes. Drug Metab Dispos. 2000;28(6): 655-660. 
44. Alyautdin R, Khalin I, Nafeeza MI, Haron MH, Kuznetsov D. Nanoscale drug delivery systems and the blood-brain barrier. Int $J$ Nanomedicine. 2014;9:795-811.

45. BatrakovaEV, MillerDW,LiS, Alakhov VY, Kabanov AV, Elmquist WF. Pluronic P85 enhances the delivery of digoxin to the brain: in vitro and in vivo studies. J Pharmacol Exp Ther. 2001;296(2):551-557.

46. Zhang X, Alakhova DY, Batrakova EV, et al. Effect of pluronic p 85 on amino acid transport in bovine brain microvessel endothelial cells. J Neuroimmune Pharmacol. 2009;4(1):35-46.

47. Batrakova EV, Li S, Li Y, Alakhov VY, Kabanov AV. Effect of pluronic P85 on ATPase activity of drug efflux transporters. Pharm Res. 2004;21(12):2226-2233.

48. BatrakovaEV,LiS, VinogradovSV, AlakhovVY, MillerDW,KabanovAV. Mechanism of pluronic effect on P-glycoprotein efflux system in blood-brain barrier: contributions of energy depletion and membrane fluidization. J Pharmacol Exp Ther. 2001;299(2):483-493.

49. Bilsky EJ, Egleton RD, Mitchell SA, et al. Enkephalin glycopeptide analogues produce analgesia with reduced dependence liability. J Med Chem. 2000;43(13):2586-2590.

50. Egleton RD, Mitchell SA, Huber JD, et al. Improved bioavailability to the brain of glycosylated Met-enkephalin analogs. Brain Res. 2000;881(1): $37-46$.

51. Morris MC, Deshayes S, Heitz F, Divita G. Cell-penetrating peptides: from molecular mechanisms to therapeutics. Biol Cell. 2008;100(4): 201-217.

52. Mager I, Eiriksdottir E, Langel K, El Andaloussi S, Langel U. Assessing the uptake kinetics and internalization mechanisms of cell-penetrating peptides using a quenched fluorescence assay. Biochim Biophys Acta. 2010;1798(3):338-343.

53. Fu A, Hui EK, Lu JZ, Boado RJ, Pardridge WM. Neuroprotection in stroke in the mouse with intravenous erythropoietin-Trojan horse fusion protein. Brain Res. 2011;1369:203-207.

54. Tamaru M, Akita H, Kajimoto K, Sato Y, Hatakeyama H, Harashima H. An apolipoprotein E modified liposomal nanoparticle: ligand dependent efficiency as a siRNA delivery carrier for mouse-derived brain endothelial cells. Int J Pharm. 2014;465(1-2):77-82.

55. Zorko M, Langel U. Cell-penetrating peptides: mechanism and kinetics of cargo delivery. Adv Drug Deliv Rev. 2005;57(4):529-545.

56. Kumagai AK, Eisenberg JB, Pardridge WM. Absorptive-mediated endocytosis of cationized albumin and a beta-endorphin-cationized albumin chimeric peptide by isolated brain capillaries. Model system of bloodbrain barrier transport. J Biol Chem. 1987;262(31):15214-15219.

57. Fernandez-Carneado J, Kogan MJ, Castel S, Giralt E. Potential peptide carriers: amphipathic proline-rich peptides derived from the N-terminal domain of gamma-zein. Angew Chem Int Ed Engl. 2004;43(14): $1811-1814$.

58. Lalatsa A, Schatzlein AG, Uchegbu IF. Strategies to deliver peptide drugs to the brain. Mol Pharm. 2014;11(4):1081-1093.

59. Ren J, Shen S, Wang D, et al. The targeted delivery of anticancer drugs to brain glioma by PEGylated oxidized multi-walled carbon nanotubes modified with angiopep-2. Biomaterials. 2012;33(11):3324-3333.

60. Kuo YC, Hong TY. Delivering etoposide to the brain using catanionic solid lipid nanoparticles with surface 5-HT-moduline. Int J Pharm. 2014;465(1-2):132-142.

61. Ye Y, Sun Y, Zhao H, et al. A novel lactoferrin-modified beta-cyclodextrin nanocarrier for brain-targeting drug delivery. Int J Pharm. 2013;458(1): 110-117.

62. Malakoutikhah M, Teixido M, Giralt E. Shuttle-mediated drug delivery to the brain. Angew Chem Int Ed Engl. 2011;50(35):7998-8014.

63. Teixido M, Zurita E, Malakoutikhah M, Tarrago T, Giralt E. Diketopiperazines as a tool for the study of transport across the blood-brain barrier (BBB) and their potential use as BBB-shuttles. J Am Chem Soc. 2007;129(38):11802-11813.

64. Malakoutikhah M, Prades R, Teixido M, Giralt E. N-methyl phenylalanine-rich peptides as highly versatile blood-brain barrier shuttles. J Med Chem. 2010;53(6):2354-2363.
65. Lasagna-Reeves C, Gonzalez-Romero D, Barria MA, et al. Bioaccumulation and toxicity of gold nanoparticles after repeated administration in mice. Biochem Biophys Res Commun. 2010;393(4):649-655.

66. Semmler-Behnke M, Kreyling WG, Lipka J, et al. Biodistribution of 1.4- and 18-nm gold particles in rats. Small. 2008;4(12): $2108-2111$

67. Sonavane G, Tomoda K, Makino K. Biodistribution of colloidal gold nanoparticles after intravenous administration: effect of particle size. Colloids Surf B Biointerfaces. 2008;66(2):274-280.

68. Hillyer JF, Albrecht RM. Correlative instrumental neutron activation analysis, light microscopy, transmission electron microscopy, and X-ray microanalysis for qualitative and quantitative detection of colloidal gold spheres in biological specimens. Microsc Microanal. 1998;4(5):481-490.

69. Hillyer JF, Albrecht RM. Gastrointestinal persorption and tissue distribution of differently sized colloidal gold nanoparticles. J Pharm Sci. 2001;90(12):1927-1936.

70. Hainfeld JF, Slatkin DN, Focella TM, Smilowitz HM. Gold nanoparticles: a new X-ray contrast agent. Br J Radiol. 2006;79(939):248-253.

71. Sadauskas E, Wallin H, Stoltenberg M, et al. Kupffer cells are central in the removal of nanoparticles from the organism. Part Fibre Toxicol. 2007;4:10.

72. De Jong WH, Hagens WI, Krystek P, Burger MC, Sips AJ, Geertsma RE. Particle size-dependent organ distribution of gold nanoparticles after intravenous administration. Biomaterials. 2008;29(12):1912-1919.

73. Chen YS, Hung YC, Lin LW, Liau I, Hong MY, Huang GS. Sizedependent impairment of cognition in mice caused by the injection of gold nanoparticles. Nanotechnology. 2010;21(48):485102.

74. Etame AB, Diaz RJ, O'Reilly MA, et al. Enhanced delivery of gold nanoparticles with therapeutic potential into the brain using MRI-guided focused ultrasound. Nanomedicine. 2012;8(7):1133-1142.

75. Hainfeld JF, Smilowitz HM, O'Connor MJ, Dilmanian FA, Slatkin DN. Gold nanoparticle imaging and radiotherapy of brain tumors in mice. Nanomedicine (Lond). 2013;8(10):1601-1609.

76. Lundqvist M, Stigler J, Elia G, Lynch I, Cedervall T, Dawson KA. Nanoparticle size and surface properties determine the protein corona with possible implications for biological impacts. Proc Natl Acad Sci US A. 2008;105(38):14265-14270.

77. Dell'Orco D, Lundqvist M, Oslakovic C, Cedervall T, Linse S. Modeling the time evolution of the nanoparticle-protein corona in a body fluid. PLoS One. 2010;5(6):e10949.

78. Arvizo RR, Giri K, Moyano D, et al. Identifying new therapeutic targets via modulation of protein corona formation by engineered nanoparticles. PLoS One. 2012;7(3):e33650.

79. Monopoli MP, Walczyk D, Campbell A, et al. Physical-chemical aspects of protein corona: relevance to in vitro and in vivo biological impacts of nanoparticles. J Am Chem Soc. 2011;133(8):2525-2534.

80. Tenzer S, Docter D, Rosfa S, et al. Nanoparticle size is a critical physicochemical determinant of the human blood plasma corona: a comprehensive quantitative proteomic analysis. ACS Nano. 2011;5(9): $7155-7167$.

81. Lundqvist M, Stigler J, Cedervall T, et al. The evolution of the protein corona around nanoparticles: a test study. ACS Nano. 2011;5(9): $7503-7509$.

82. Dobrovolskaia MA, Aggarwal P, Hall JB, McNeil SE. Preclinical studies to understand nanoparticle interaction with the immune system and its potential effects on nanoparticle biodistribution. Mol Pharm. 2008;5(4):487-495.

83. Reddy JS, Venkateswarlu V. Novel delivery systems for drug targeting to the brain. Drugs Future. 2004;29(1):63-83.

84. Kreuter J. Influence of the surface properties on nanoparticle-mediated transport of drugs to the brain. J Nanosci Nanotechnol. 2004;4(5): 484-488.

85. Lacerda SH, Park JJ, Meuse C, et al. Interaction of gold nanoparticles with common human blood proteins. ACS Nano. 2010;4(1): 365-379. 
86. Dermietzel R, Spray DC, Nedergaard M. Front matter, in blood-brain barriers: from ontogeny to artificial interfaces. Blood-Brain Barriers. Vol. 1. Weinheim, Germany: Wiley-VCH Verlag GmbH \& Co. KGaA; 2007:I-XXXII

87. Kreuter J. Drug delivery to the central nervous system by polymeric nanoparticles: what do we know? Adv Drug Deliv Rev. 2013;71: 2-14.

88. Alvarez-Lorenzo C, Sosnik A, Concheiro A. PEO-PPO block copolymers for passive micellar targeting and overcoming multidrug resistance in cancer therapy. Curr Drug Targets. 2011;12(8):1112-1130.

89. Gao X, Wu B, Zhang Q, et al. Brain delivery of vasoactive intestinal peptide enhanced with the nanoparticles conjugated with wheat germ agglutinin following intranasal administration. J Control Release. 2007; 121(3):156-167.

90. Geldenhuys W, Mbimba T, Bui T, Harrison K, Sutariya V. Braintargeted delivery of paclitaxel using glutathione-coated nanoparticles for brain cancers. J Drug Target. 2011;19(9):837-845.

91. Hu K, Shi Y, Jiang W, Han J, Huang S, Jiang X. Lactoferrin conjugated PEG-PLGA nanoparticles for brain delivery: preparation, characterization and efficacy in Parkinson's disease. Int J Pharm. 2011;415(1-2):273-283.

92. Hu Q, Gu G, Liu Z, et al. F3 peptide-functionalized PEG-PLA nanoparticles co-administrated with tLyp-1 peptide for anti-glioma drug delivery. Biomaterials. 2013;34(4):1135-1145.

93. Huang S, Li J, Han L, et al. Dual targeting effect of angiopep-2modified, DNA-loaded nanoparticles for glioma. Biomaterials. 2011; 32(28):6832-6838.

94. Kanazawa T, Akiyama F, Kakizaki S, Takashima Y, Seta Y. Delivery of siRNA to the brain using a combination of nose-to-brain delivery and cell-penetrating peptide-modified nano-micelles. Biomaterials. 2013;34(36):9220-9226.

95. Ke W, Shao K, Huang R, et al. Gene delivery targeted to the brain using an angiopep-conjugated polyethyleneglycol-modified polyamidoamine dendrimer. Biomaterials. 2009;30(36):6976-6985.

96. Kim JY, Choi WI, Kim YH, Tae G. Brain-targeted delivery of protein using chitosan- and RVG peptide-conjugated, pluronic-based nanocarrier. Biomaterials. 2013;34(4):1170-1178.

97. Kuang Y, An S, Guo Y, et al. T7 peptide-functionalized nanoparticles utilizing RNA interference for glioma dual targeting. Int J Pharm. 2013;454(1):11-20.

98. Kuo YC, Yu HW. Transport of saquinavir across human brainmicrovascular endothelial cells by poly(lactide-co-glycolide) nanoparticles with surface poly-(gamma-glutamic acid). Int $J$ Pharm. 2011;416(1):365-375.

99. Li J, Zhang $\mathrm{C}$, Li J, et al. Brain delivery of NAP with PEG-PLGA nanoparticles modified with phage display peptides. Pharm Res. 2013;30(7): 1813-1823.

100. Liu L, Guo K, Lu J, et al. Biologically active core/shell nanoparticles self-assembled from cholesterol-terminated PEG-TAT for drug delivery across the blood-brain barrier. Biomaterials. 2008;29(10): 1509-1517.

101. Liu L, Venkatraman SS, Yang YY, et al. Polymeric micelles anchored with TAT for delivery of antibiotics across the blood-brain barrier Biopolymers. 2008;90(5):617-623.

102. Liu Y, Guo Y, An S, et al. Targeting caspase-3 as dual therapeutic benefits by RNAi facilitating brain-targeted nanoparticles in a rat model of Parkinson's disease. PLoS One. 2013;8(5):e62905.

103. Liu Z, Gao X, Kang T, et al. B6 peptide-modified PEG-PLA nanoparticles for enhanced brain delivery of neuroprotective peptide. Bioconjug Chem. 2013;24(6):997-1007.

104. Liu Z, Jiang M, Kang T, et al. Lactoferrin-modified PEG-co-PCL nanoparticles for enhanced brain delivery of NAP peptide following intranasal administration. Biomaterials. 2013;34(15):3870-3881.

105. Mathew A, Fukuda T, Nagaoka Y, et al. Curcumin loaded-PLGA nanoparticles conjugated with Tet-1 peptide for potential use in Alzheimer's disease. PLoS One. 2012;7(3):e32616.
106. Suk JS, Suh J, Choy K, Lai SK, Fu J, Hanes J. Gene delivery to differentiated neurotypic cells with RGD and HIV Tat peptide functionalized polymeric nanoparticles. Biomaterials. 2006;27(29):5143-5150.

107. Tian XH, Wang ZG, Meng H, et al. Tat peptide-decorated gelatinsiloxane nanoparticles for delivery of CGRP transgene in treatment of cerebral vasospasm. Int J Nanomedicine. 2013;8:865-876.

108. Tosi G, Costantino L, Rivasi F, et al. Targeting the central nervous system: in vivo experiments with peptide-derivatized nanoparticles loaded with Loperamide and Rhodamine-123. J Control Release. 2007;122(1):1-9.

109. Xin H, Sha X, Jiang X, Zhang W, Chen L, Fang X. Anti-glioblastoma efficacy and safety of paclitaxel-loading angiopep-conjugated dual targeting PEG-PCL nanoparticles. Biomaterials. 2012;33(32): $8167-8176$

110. Guerrero S, Araya E, Fiedler JL, et al. Improving the brain delivery of gold nanoparticles by conjugation with an amphipathic peptide. Nanomedicine. 2010;5(6):897-913.

111. Guerrero S, Herance JR, Rojas S, et al. Synthesis and in vivo evaluation of the biodistribution of a $18 \mathrm{~F}$-labeled conjugate gold-nanoparticlepeptide with potential biomedical application. Bioconjug Chem. 2012;23(3):399-408.

112. Soto C, Sigurdsson EM, Morelli L, Kumar RA, Castano EM, Frangione B. Beta-sheet breaker peptides inhibit fibrillogenesis in a rat brain model of amyloidosis: implications for Alzheimer's therapy. Nat Med. 1998;4(7):822-826.

113. Deane R, Wu Z, Zlokovic BV. RAGE (yin) versus LRP (yang) balance regulates alzheimer amyloid beta-peptide clearance through transport across the blood-brain barrier. Stroke. 2004;35(11 suppl 1): 2628-2631.

114. Deane R, Du Yan S, Submamaryan RK, et al. RAGE mediates amyloidbeta peptide transport across the blood-brain barrier and accumulation in brain. Nat Med. 2003;9(7):907-913.

115. Prades R, Guerrero S, Araya E, et al. Delivery of gold nanoparticles to the brain by conjugation with a peptide that recognizes the transferrin receptor. Biomaterials. 2012;33(29):7194-7205.

116. Day ES, Zhang L, Thompson PA, et al. Vascular-targeted photothermal therapy of an orthotopic murine glioma model. Nanomedicine. 2012;7(8): 1133-1148.

117. Walters R, Kraig RP, Medintz I, et al. Nanoparticle targeting to neurons in a rat hippocampal slice culture model. ASN Neuro. 2012;4(6): 383-392.

118. Glat M, Skaat H, Menkes-Caspi N, Margel S, Stern EA. Age-dependent effects of microglial inhibition in vivo on Alzheimer's disease neuropathology using bioactive-conjugated iron oxide nanoparticles. J Nanobiotechnology. 2013;11:32.

119. Schulz F, Lutz D, Rusche N, et al. Gold nanoparticles functionalized with a fragment of the neural cell adhesion molecule L1 stimulate L1-mediated functions. Nanoscale. 2013;5(21):10605-10617.

120. Wadghiri YZ, Li J, Wang J, et al. Detection of amyloid plaques targeted by bifunctional USPIO in Alzheimer's disease transgenic mice using magnetic resonance microimaging. PLoS One. 2013;8(2):e57097.

121. Lu W, Melancon MP, Xiong C, et al. Effects of photoacoustic imaging and photothermal ablation therapy mediated by targeted hollow gold nanospheres in an orthotopic mouse xenograft model of glioma. Cancer Res. 2011;71(19):6116-6121.

122. Frigell J, Garcia I, Gomez-Vallejo V, Llop J, Penades S. 68Ga-labeled gold glyconanoparticles for exploring blood-brain barrier permeability: preparation, biodistribution studies, and improved brain uptake via neuropeptide conjugation. J Am Chem Soc. 2014;136(1):449-457.

123. Ono M, Cheng Y, Kimura H, et al. Novel 18F-labeled benzofuran derivatives with improved properties for positron emission tomography (PET) imaging of beta-amyloid plaques in Alzheimer's brains. $J$ Med Chem. 2011;54(8):2971-2979.

124. Schäffler M, Sousa F, Wenk A, et al. Blood protein coating of gold nanoparticles as potential tool for organ targeting. Biomaterials. 2014;35(10): 3455-3466. 
125. Shilo M, Motiei M, Hana P, Popovtzer R. Transport of nanoparticles through the blood-brain barrier for imaging and therapeutic applications. Nanoscale. 2014;6(4):2146-2152.

126. Riveros A, Dadlani K, Salas E, Caballero L, Melo F, Kogan MJ. Gold nanoparticle-membrane interactions: implications in biomedicine. J Biomater Tissue Eng. 2013;3(1):4-21.

127. Olmedo I, Araya E, Sanz F, et al. How changes in the sequence of the peptide CLPFFD-NH2 can modify the conjugation and stability of gold nanoparticles and their affinity for beta-amyloid fibrils. Bioconjug Chem. 2008;19(6):1154-1163.

128. Bower PV, Louie EA, Long JR, Stayton PS, Drobny GP. Solid-state NMR structural studies of peptides immobilized on gold nanoparticles. Langmuir. 2005;21(7):3002-3007.

129. Barth A. Infrared spectroscopy of proteins. Biochim Biophys Acta. 2007;1767(9):1073-1101.

130. Kurouski D, Postiglione T, Deckert-Gaudig T, Deckert V, Lednev IK. Amide I vibrational mode suppression in surface (SERS) and tip (TERS) enhanced Raman spectra of protein specimens. Analyst. 2013;138(6): 1665-1673.

131. Arif M, Karthigeyan D, Siddhanta S, Kumar GVP, Narayana C, Kundu T. Analysis of protein acetyltransferase structure-function relation by surface-enhanced Raman scattering (SERS): a tool to screen and characterize small molecule modulators. In: Hake SB, Janzen CJ, editors. Protein Acetylation. Vol. 981. Humana Press; 2013:239-261.
132. Alam MI, Beg S, Samad A, et al. Strategy for effective brain drug delivery. Eur J Pharm Sci. 2010;40(5):385-403.

133. Gizurarson $\mathrm{S}$. Anatomical and histological factors affecting intranasal drug and vaccine delivery. Curr Drug Deliv. 2012;9(6):566-582.

134. Illum L. Nasal drug delivery - possibilities, problems and solutions. J Control Release. 2003;87(1-3):187-198.

135. Mistry A, Stolnik S, Illum L. Nanoparticles for direct nose-to-brain delivery of drugs. Int J Pharm. 2009;379(1):146-157.

136. Wolstenholme GEW, Knight J, Foundation C. Taste and Smell in Vertebrates. Churchill; 1970.

137. Joshi HM, Bhumkar DR, Joshi K, Pokharkar V, Sastry M. Gold nanoparticles as carriers for efficient transmucosal insulin delivery. Langmuir. 2006;22(1):300-305.

138. Hutter E, Boridy S, Labrecque S, et al. Microglial response to gold nanoparticles. ACS Nano. 2010;4(5):2595-2606.

139. Kozlovskaya L, Abou-Kaoud M, Stepensky D. Quantitative analysis of drug delivery to the brain via nasal route. J Control Release. 2014;189: 133-140.

140. Arora P, Sharma S, Garg S. Permeability issues in nasal drug delivery. Drug Discov Today. 2002;7(18):967-975.

141. Freese C, Uboldi C, Gibson MI, et al. Uptake and cytotoxicity of citrate-coated gold nanospheres: comparative studies on human endothelial and epithelial cells. Part Fibre Toxicol. 2012;9:23.
International Journal of Nanomedicine

\section{Publish your work in this journal}

The International Journal of Nanomedicine is an international, peerreviewed journal focusing on the application of nanotechnology in diagnostics, therapeutics, and drug delivery systems throughout the biomedical field. This journal is indexed on PubMed Central, MedLine, CAS, SciSearch ${ }^{\circledR}$, Current Contents ${ }^{\circledR} /$ Clinical Medicine,

\section{Dovepress}

Journal Citation Reports/Science Edition, EMBase, Scopus and the Elsevier Bibliographic databases. The manuscript management system is completely online and includes a very quick and fair peer-review system, which is all easy to use. Visit http://www.dovepress.com/ testimonials.php to read real quotes from published authors. 